Wright State University

CORE Scholar

2016

\title{
The Effects of Micro-Dimple Texture on the Friction and Thermal Behavior of a Point Contact
}

Utsav Kamleshbhai Parmar

Wright State University

Follow this and additional works at: https://corescholar.libraries.wright.edu/etd_all

Part of the Mechanical Engineering Commons

\section{Repository Citation}

Parmar, Utsav Kamleshbhai, "The Effects of Micro-Dimple Texture on the Friction and Thermal Behavior of a Point Contact" (2016). Browse all Theses and Dissertations. 1478.

https://corescholar.libraries.wright.edu/etd_all/1478

This Thesis is brought to you for free and open access by the Theses and Dissertations at CORE Scholar. It has been accepted for inclusion in Browse all Theses and Dissertations by an authorized administrator of CORE Scholar. For more information, please contact library-corescholar@wright.edu. 


\title{
The Effects of Micro-dimple Texture on the Friction and Thermal Behavior of a Point Contact
}

\author{
A thesis submitted in partial fulfillment \\ Of the requirements for the degree of \\ Master of Science in Mechanical Engineering
}

By

Parmar Utsav AKA Sagar Kamleshbhai

B.Tech., Ganpat University, 2013

2016

Wright State University 


\section{WRIGHT STATE UNIVERSITY}

GRADUATE SCHOOL

$\underline{04 / 22 / 2016}$

I HEREBY RECOMMEND THAT THE THESIS PREPARED UNDER MY SUPERVISION BY Parmar Utsav AKA Sagar Kamleshbhai ENTITLED The Effects of Microdimple Texture on the Friction and Thermal Behavior of a Point Contact BE ACCEPTED IN PARTIAL FULFILLMENT OF THE REQUIREMENTS FOR THE DEGREE OF Master of Science in Mechanical Engineering.

\begin{tabular}{c}
\hline $\begin{array}{c}\text { Sheng Li, Ph.D. } \\
\text { Thesis Director }\end{array}$ \\
\hline George P.G. Huang, Ph.D. \\
Department Chair
\end{tabular}

Committee on Final Examination

Sheng Li, Ph.D.

Ahsan Mian, Ph.D.

Nikolai V. Priezjev, Ph.D.

Robert E. W. Fyffe, Ph.D.

Vice President for Research and

Dean of the Graduate School 


\begin{abstract}
Parmar, Utsav AKA Sagar Kamleshbhai. M.S.M.E., Department of Mechanical and Materials Engineering, Wright State University, 2016. The Effects of Micro-dimple Texture on the Friction and Thermal Behavior of a Point Contact
\end{abstract}

This study investigates the effects of the micro-dimple texture on the friction and surface temperature performances of a ball-on-disk contact, operating under the speed and load ranges that cover typical gearing applications. Circular shaped micro-dimple arrays with different dimple center distances and dimple depths are implemented on the ball surface to quantify the impacts of these two parameters on the friction coefficient and the maximum ball surface temperature. In addition, the contacts of three surface texture combinations, namely micro-dimpled and polished ball surface versus polished disk surface, polished ball surface versus polished disk surface and ground ball surface versus ground disk surface, are compared to demonstrate any beneficial or detrimental effect of micro-dimples in heavily loaded high speed applications. This study adopts a thermal mixed EHL point contact model, whose capability and accuracy have been well demonstrated by comparing to the experimental measurements, to quantify the deterministic tribological behavior within the contact, allowing the exploration of the underlying mechanism that governs the role of micro-dimples in the elastohydrodynamic lubrication. 


\section{TABLE OF CONTENTS}

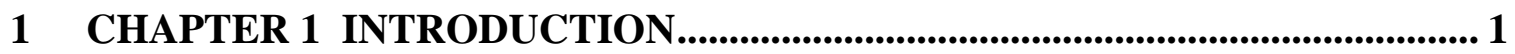

$1.1 \quad$ Background and Motivation ..................................................................... 1

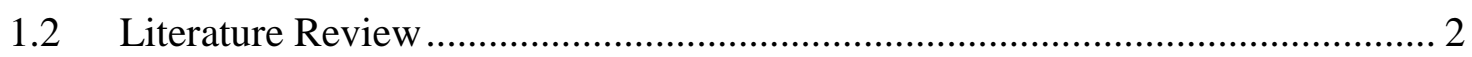

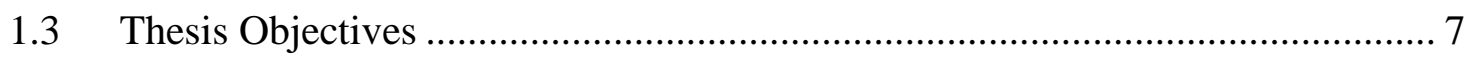

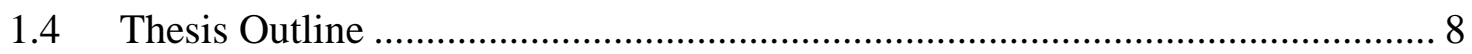

2 CHAPTER 2 A THERMAL MIXED EHL MODEL FOR POINT CONTACTS

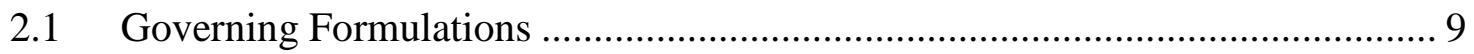

$2.2 \quad$ Numerical Solution Procedures..................................................................... 14

3 CHAPTER 3 SIMULATIONS AND DISCUSSION …....................................... 16

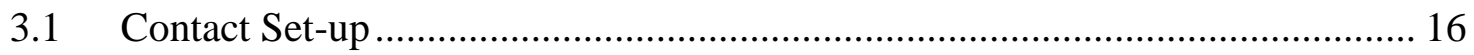

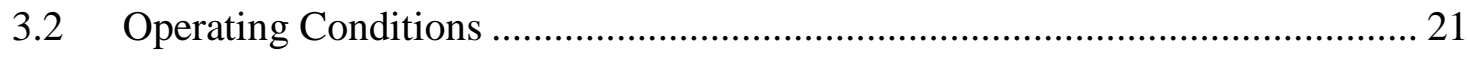

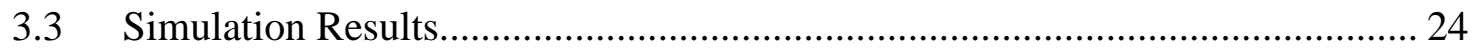

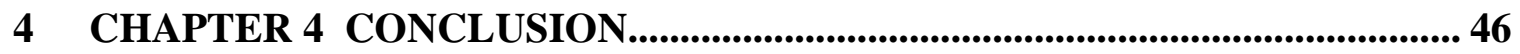

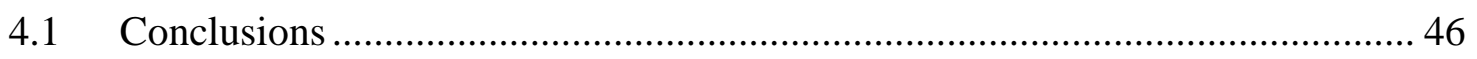

4.2 Recommendation for Future Work ............................................................... 47

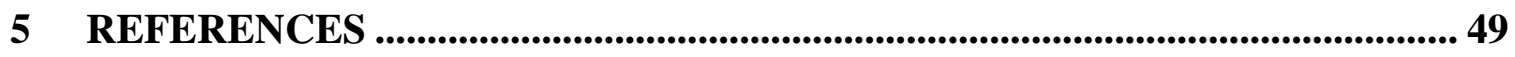




\section{LIST OF FIGURES}

Figure 2-1 Flowchart of the thermal mixed EHL computation. .................................. 15

Figure 3-1 The contact set-up between a circular ball and a flat disk ........................... 17

Figure 3-2 The surface topographies of (a) ball specimen and (b) disk specimen for the type

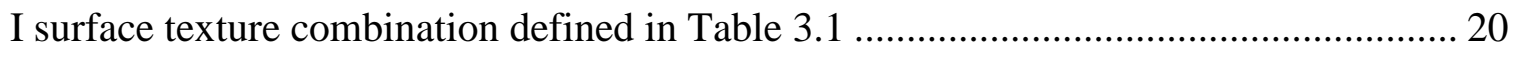

Figure 3-3 The surface topography of the ground surface........................................ 22

Figure 3-4 The variations of $W$ and $p_{h}$ with time for one complete ball-on-disk contact

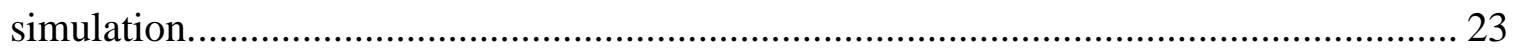

Figure 3-5 The distributions of (a) asperity contacts, (b) contact pressure, (c) lubricant temperature and (d) ball surface temperature within the Hertzian zone. The surface texture combination is Type I of Table 3.1. The micro-dimple array is Case $H^{a} D^{a}$ of Table 3.2. $u_{r}=10 \mathrm{~m} / \mathrm{s}$ and $p_{h}=2.5 \mathrm{GPa}$. 26

Figure 3-6 The comparisons of (a) $\bar{\mu}$ and (b) $\bar{T}_{1}^{\max }$ between the micro-dimple array Cases $H^{a} D^{a}, H^{a} D^{b}$ and $H^{a} D^{c}$ (defined in Table 3.2) for the type I surface texture combination

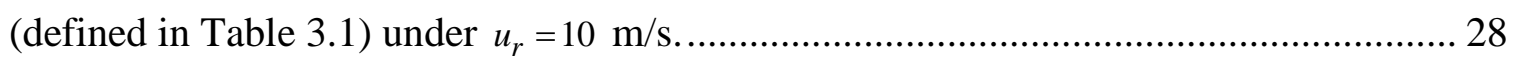

Figure 3-7 The comparison of the asperity contact activity (left column) and the contact pressure (right column) between the micro-dimple array cases (a) $H^{a} D^{a}$, (b) $H^{a} D^{b}$ and (c) $H^{a} D^{c}$ within the Hertzian Zone. The surface texture combination is Type I of Table 3.1. $u_{r}=10 \mathrm{~m} / \mathrm{s}$, and $p_{h}=2.5 \mathrm{GPa}$. 
Figure 3-8 The comparisons of (a) $\bar{\mu}$ and (b) $\bar{T}_{1}^{\max }$ between the micro-dimple array Cases $H^{b} D^{a}, H^{b} D^{b}$ and $H^{b} D^{c}$ (defined in Table 3.2) for the type I surface texture combination (defined in Table 3.1) under $u_{r}=10 \mathrm{~m} / \mathrm{s}$ 30

Figure 3-9 The comparisons of (a) $\bar{\mu}$ and (b) $\bar{T}_{1}^{\text {max }}$ between the micro-dimple array Cases $H^{c} D^{a}, H^{c} D^{b}$, and $H^{c} D^{c}$ (defined in Table 3.2) for the type I surface texture combination (defined in Table 3.1) under $u_{r}=10 \mathrm{~m} / \mathrm{s}$. 31

Figure 3-10 The comparisons of (a) $\bar{\mu}$ and (b) $\bar{T}_{1}^{\max }$ between the micro-dimple array Cases $H^{a} D^{a}, H^{a} D^{b}$ and $H^{a} D^{c}$ (defined in Table 3.2) for the type I surface texture combination (defined in Table 3.1) under $u_{r}=5 \mathrm{~m} / \mathrm{s}$. 32

Figure 3-11 The comparisons of (a) $\bar{\mu}$ and (b) $\bar{T}_{1}^{\max }$ between the micro-dimple array Cases $H^{b} D^{a}, H^{b} D^{b}$ and $H^{b} D^{c}$ (defined in Table 3.2) for the type I surface texture combination (defined in Table 3.1) under $u_{r}=5 \mathrm{~m} / \mathrm{s}$ 33

Figure 3-12 The comparisons of (a) $\bar{\mu}$ and (b) $\bar{T}_{1}^{\max }$ between the micro-dimple array Cases $H^{c} D^{a}, H^{c} D^{b}$ and $H^{c} D^{c}$ (defined in Table 3.2) for the type I surface texture combination (defined in Table 3.1) under $u_{r}=5 \mathrm{~m} / \mathrm{s}$. 34

Figure 3-13 The comparisons of (a) $\bar{\mu}$ and (b) $\bar{T}_{1}^{\max }$ between the micro-dimple array Cases $H^{a} D^{a}, H^{a} D^{b}$ and $H^{a} D^{c}$ (defined in Table 3.2) for the type I surface texture combination (defined in Table 3.1) under $u_{r}=0.5 \mathrm{~m} / \mathrm{s}$. 35 
Figure 3-14 The comparisons of (a) $\bar{\mu}$ and (b) $\bar{T}_{1}^{\max }$ between the micro-dimple array Cases $H^{b} D^{a}, H^{b} D^{b}$ and $H^{b} D^{c}$ (defined in Table 3.2) for the type I surface texture combination (defined in Table 3.1) under $u_{r}=0.5 \mathrm{~m} / \mathrm{s}$ 36

Figure 3-15 The comparisons of (a) $\bar{\mu}$ and (b) $\bar{T}_{1}^{\max }$ between the micro-dimple array Cases $H^{c} D^{a}, H^{c} D^{b}$ and $H^{c} D^{c}$ (defined in Table 3.2) for the type I surface texture combination (defined in Table 3.1) under $u_{r}=0.5 \mathrm{~m} / \mathrm{s}$. 37

Figure 3-16 The variations of $\bar{\mu}$ (left column) and $\bar{T}_{1}^{\max }$ (right column) with the dimple center distance $D$ and the dimple depth $H$ at the rolling velocities (a) $u_{r}=10 \mathrm{~m} / \mathrm{s}$, (b) $u_{r}=5$ $\mathrm{m} / \mathrm{s}$ and (c) $u_{r}=0.5 \mathrm{~m} / \mathrm{s}$ and the lowest loading stage $p_{h}=0.5 \mathrm{GPa}$ for the type I surface

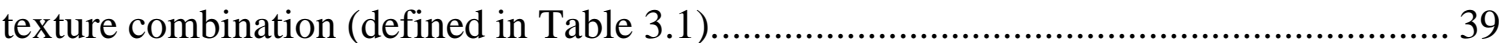

Figure 3-17 The variations of $\bar{\mu}$ (left column) and $\bar{T}_{1}^{\max }$ (right column) with the dimple center distance $D$ and the dimple depth $H$ at the rolling velocities (a) $u_{r}=10 \mathrm{~m} / \mathrm{s}$, (b) $u_{r}=5$ $\mathrm{m} / \mathrm{s}$ and (c) $u_{r}=0.5 \mathrm{~m} / \mathrm{s}$ and the median loading stage $p_{h}=1.5 \mathrm{GPa}$ for the type I surface

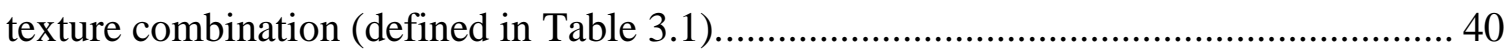
Figure 3-18 The variations of $\bar{\mu}$ (left column) and $\bar{T}_{1}^{\max }$ (right column) with the dimple center distance $D$ and the dimple depth $H$ at the rolling velocities (a) $u_{r}=10 \mathrm{~m} / \mathrm{s}$, (b) $u_{r}=5$ $\mathrm{m} / \mathrm{s}$ and (c) $u_{r}=0.5 \mathrm{~m} / \mathrm{s}$ and the highest loading stage $p_{h}=2.5 \mathrm{GPa}$ for the type I surface

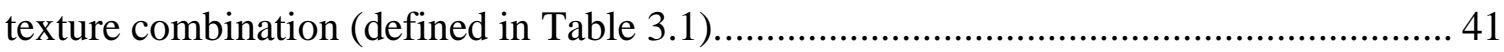


Figure 3-19 The comparisons of $\bar{\mu}$ between Type I (with $H^{a} D^{a}$ dimple array), II and III surface texture combinations under (a) $u_{r}=10 \mathrm{~m} / \mathrm{s}$, (b) $u_{r}=5 \mathrm{~m} / \mathrm{s}$ and (c) $u_{r}=0.5 \mathrm{~m} / \mathrm{s} . .43$ Figure 3-20 The comparisons of the asperity contact activity (left column) and the contact pressure (right column) between the surface texture combinations of (a) Type I with $H^{a} D^{a}$ dimple array, (b) Type II and (c) Type III within the Hertzian zone. $u_{r}=10 \mathrm{~m} / \mathrm{s}$, and

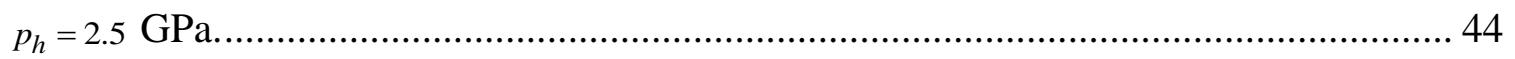

Figure 3-21 The comparisons of $\bar{T}_{1}^{\max }$ between Type I (with $H^{a} D^{a}$ dimple array), II and III surface texture combinations under (a) $u_{r}=10 \mathrm{~m} / \mathrm{s}$, (b) $u_{r}=5 \mathrm{~m} / \mathrm{s}$ and (c) $u_{r}=0.5 \mathrm{~m} / \mathrm{s}$. 45 


\section{LIST OF TABLES}

Table 3-1 List of the surface texture conditions of the contact pair. ............................. 18 Table 3-2 Definition of simulation case numbers for different combinations of dimple

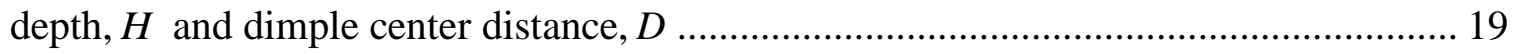




\section{ACKNOWLEDGEMENTS}

I would like to express my sincere gratitude to Dr. Sheng Li for believing in me and giving me this opportunity. He is full of knowledge and mentored me through the project. I gained tremendous amount of knowledge from him. He is so supportive and encouraged me all the way from the beginning.

I would like to thank my committee members (Drs. Ahsan Mian and Nikolai Priezjev) for their kindness and time. I would also like to thank Anusha Anisetti for guiding me through things and for spending her time enlarging the scope of my work.

Last but most importantly to my Parents, my Sister Dhruva, my Brother Ronak and

my Fiancé Srushti for being so supportive from the beginning and for making what I am today. Their love and belief in me made me pursue Masters in this esteemed university.

This study was sponsored by the Research Initiation Grant of the Wright State University. 
Dedicated to my parents 


\section{CHAPTER 1}

\section{INTRODUCTION}

\subsection{Background and Motivation}

The micro-scale surface topography of rolling mechanical elements (bearings and gears for example) plays an important role in the frictional power loss [1-4], the surface wear [5, 6], the rolling contact fatigue (micro and macro scale pitting) failure [7-12], and the surface temperature related scuffing failure [13-15]. In the heavily loaded contacts of gearing applications, the presence of the significant surface roughness profiles (tool marks) due to the finishing processes, such as shaving and grinding, introduces frequent asperity Contacts within the elastohydrodynamic lubrication (EHL) conjunction. These localized asperity contacts coexist with the surrounding hydrodynamic fluid film, sharing the normal contact load. Such a lubrication condition is commonly referred as the mixed EHL [16]. Owing to the asperity contacts, the lubrication film breaks down, where not only the surface tractions but also the surface temperature peak, dictating the friction [1-3], and the failures of fatigue [11] and scuffing [15]. To improve the rolling contact performances in these 
aspects, the surface polishing process that eliminates the local roughness peaks has been shown to be a successful method [1, 17-21]. The reduced roughness amplitude results in a more continuous lubrication film, decreasing the possibility of asperity contacts. A potential alternative to the surface polishing method is the micro-surface-texturing approach, which implements arranged micro-dimples of various shapes and patterns onto the contact surfaces [4]. These dimples contribute mainly by acting as lubricant reservoirs to provide lubricant under the starved lubrication condition (for instance, when the surface velocities are low or the surface roughness is significant), and micro-hydrodynamic bearings to provide additional load-carrying capacity (when the surface velocities are sufficiently high to allow hydrodynamic effects). In addition, the dimples can trap wear particles to reduce the third-body induced surface stress concentrations, friction and wear. This study thus aims at quantifying the impacts of micro-dimples on the tribological behavior using a deterministic elastohydrodynamic model under typical gearing application operating conditions.

\subsection{Literature Review}

In literature, a large group of works have been carried out, focusing on the effects of the surface texturing on the friction and wear behavior under the relatively low speed and/or low load condition for seal and thrust bearing type of applications [4, 22]. Kovalchenko et al. [23] measured the friction of a unidirectional sliding contact under the speed range of 0.015 to $0.75 \mathrm{~m} / \mathrm{s}$ and the load range of 0.16 to $1.6 \mathrm{MPa}$, utilizing a flat-pin-on-disk set-up. The friction coefficient was successfully reduced by implementing the laser textured dimples onto the disk surface. The most significant reduction was observed when the 
sliding speed was at the low end of the adopted speed range. At the high end of the speed range, however, the advantage of the dimple texture diminished. Andersson et al. [24] measured the friction coefficient and the wear scar of the contact between a stationary ball and an oscillating disk, with the sliding speed being limited between $0.04 \mathrm{~m} / \mathrm{s}$ and 0.16 $\mathrm{m} / \mathrm{s}$. Under the starved lubrication condition, the laser-textured disk was shown to be able to improve the friction and wear performance significantly in comparison to the nontextured surface. It was also found the improvement was lubricant viscosity dependent. For the low viscosity lubricant, the micro surface texture lost its effectiveness at the high end of the sliding speed range considered. Galda et al. [25] investigated the impacts of the surface texturing on the Stribeck curve considering the contact between a stationary bearing sleeve and a rotating ring under the constant load of $18 \mathrm{MPa}$ and the sliding speed range of 0.08 to $0.69 \mathrm{~m} / \mathrm{s}$. The different dimple shapes were implemented onto the ground surfaces, which have the RMS roughness amplitude $R_{q}=0.32 \mu \mathrm{m}$. It was shown the dimples were able to decrease the friction coefficient largely under the poorly lubricated condition. The important roles of the shape and the distribution of the dimples in friction reduction were also demonstrated. Qiu and Khonsari [26] examined the friction coefficient performance of the contact formed by a stationary textured ring and a rotating non-textured counterpart. It was observed the presence of the dimple texture can effectively reduce the friction coefficient under the low loading condition. However, such improvement decreased with the increase of the normal load. Segu et al. [27] applied hybrid dimple arrays that consists of circular and elliptical micro-dimples to a flat-on-flat contact, achieving the reduction in friction within the speed range of 0.09 to $0.55 \mathrm{~m} / \mathrm{s}$. 
Wang et al. [28] studied the influence of the dimple size on the friction response of a line contact within the sliding velocity range of 0.02 to $0.21 \mathrm{~m} / \mathrm{s}$ under the low loading condition. The results suggested the dimple size was a critical factor and there existed the optimum dimple size, which corresponded to the high hydrodynamic load-carrying capacity and the low friction coefficient. Using a reciprocating tribo-meter, Tang et al. [29] investigated the influence of the dimple density on the friction and wear reduction under the contact pressure of $8.3 \mathrm{MPa}$ and the sliding velocity of $0.24 \mathrm{~m} / \mathrm{s}$. In general, the friction of the contact was first observed to decrease with the decrease of the dimple density. However, this trend reversed when the excessive reduction in the dimple density is encountered. This finding is line with the other studies [23-25].

In addition to the above experimental studies, the numerical and computational method has also been used for the quantification of the micro-surface-texture effect on the tribological behavior. Through numerical simulations, Wang et al. [28] showed the hydrodynamic pressure generation of the surface dimples was tightly related to the dimple size. Tang et al. [29] demonstrated the strong influence of the adjacent dimple interactions on the hydrodynamic pressure. Yu et al. [30] found the geometric shapes and orientations of dimples have an evident impact on the load-carrying capacity, while considering a single dimple instead of a dimple array on the surface. Brunetiere and Tournerie [31] simulated the hydrodynamic lift mechanism of a mechanical seal with textured surfaces, pointing to the importance of the dimple geometry and density in the friction reduction.

Another group of works extended the investigation of the effectiveness of the surface texturing in the enhancement of the tribological performance from the low load to the medium load range, while maintaining the low surface speed condition. Segu and Kim 
[32] expanded an earlier study [27] from the conformal contact to the non-conformal point contact, with the maximum Hertzian pressure increased to the range of 0.39 to $0.96 \mathrm{GPa}$. It was shown the decrease in friction was still evident with the presence of the hybrid dimple arrays under the speed range of 0.09 to $0.55 \mathrm{~m} / \mathrm{s}$. Employing a twin-disk contact set-up, Nakatsuji and Mori [13] examined the rolling contact performance of micro-dented surfaces in both the fatigue and scuffing aspects under the two maximum Hertzian pressure levels of 0.28 and $0.66 \mathrm{GPa}$ and the rolling velocity of $0.6 \mathrm{~m} / \mathrm{s}$. The positive impacts of the micro-dents were demonstrated. Wakuda et al. [33] studied the influences of the dimple size, density, and shape on the friction behavior of a contact formed by the textured ceramic disk and the non-textured steel pin under the contact pressure of $0.78 \mathrm{GPa}$ and the sliding speed ranging from 0.012 to $1.2 \mathrm{~m} / \mathrm{s}$. The results showed the effects of the dimple size and density on the friction reduction were similar to those under the low loading condition [23$25,29]$. The shape of the dimple, however, was found to have negligible impact on the friction, contradicting the findings of Galda et al. [25] and Yu et al. [30] where the loads were much lower. Instead of relying on the experimental measurements, Meng et al. [34] numerically simulated the friction behavior of parallel surfaces, and found that the effectiveness of micro-dimples on the friction reduction was dependent on both the operating condition and the surface roughness condition. Evident decreases in the friction coefficient were observed when the ratio of the minimum film thickness to the roughness amplitude was small, i.e. a poor lubrication condition.

Although these studies showed the potential of the micro surface dimples under the medium loading range, some other works observed the contrary. For example, Kovalchenko et al. [5] extended their work from the conformal contact [23] to the non- 
conformal contact under the increased normal load of $0.7 \mathrm{GPa}$ with the same speed range of 0.015 to $0.75 \mathrm{~m} / \mathrm{s}$. It was observed the textured surfaces ( $5 \mu \mathrm{m}$ depth dimple arrays) introduced higher wear rates and higher friction coefficients in comparing to the nontextured surfaces. As the tests continued, the accelerated wear changed the contact geometry and alleviated the contact pressure, resulting in the friction coefficient reduction. A third group of studies further increased the contact load to the high pressure range. Considering the contact between needle rollers and rings under the maximum Hertzian pressure of 2.5GPa, Akamatsu et al. [7] elongated the rolling contact fatigue life through surface texturing under the starved lubrication condition. Borrowing the contact set-up of Akamatsu et al. [7], Zhai et al. [8] showed the surface dents had adverse impacts on the fatigue life when the contact was well-lubricated. Krupka et al. [9] showed the shallow dents with the depth of 0.2 to $0.3 \mu \mathrm{m}$ failed to elongate the rolling contact fatigue life when the load was above $3.5 \mathrm{GPa}$ and the rolling velocity was above $4 \mathrm{~m} / \mathrm{s}$, although the same dents were found to be able to improve the lubrication under the load of $0.505 \mathrm{GPa}$ and the very low speed levels of 0.0013 and $0.0054 \mathrm{~m} / \mathrm{s}$. When the dent depth was further increased to $20 \mu \mathrm{m}$, the fatigue life was significantly reduced. A similar study that yielded the same observation was performed by Vrbka et al. [10]. These works [8-10] concluded the enhancement of the fatigue life through surface denting could only be achieved when the contact experienced the very poor lubrication condition, where the lubricant reservoir mechanism of the micro-dents take effect. 


\subsection{Thesis Objectives}

In view of the literature above, most of the studies have been focusing on the applications of the micro-surface-texturing under the low to medium speed range and/or low to medium load range, which hardly represent the common operating condition of gear Contacts. Therefore, the specific technical objectives of this study are summarized as below:

- Investigate the effects of micro-dimples on the friction and surface temperature performances of a lubricated point contact, which operates under the speed ranging from 0.5 to $10 \mathrm{~m} / \mathrm{s}$ and the load ranging from 0.5 to $2.5 \mathrm{GPa}$, using the thermal mixed EHL point contact model proposed by Li et al. [15],

- Employing a ball-on-disk contact, the micro-dimple arrays with different dimple center distances and dimple depths will be implemented on the ball surface to quantify the impacts of these two parameters on the friction coefficient and the maximum ball surface temperature.

- The contacts of three surface texture combinations, namely micro-dimpled and polished ball surface versus polished disk surface, polished ball surface versus polished disk surface and ground ball surface versus ground disk surface, will be compared to demonstrate any beneficial or detrimental effect of micro-dimples in heavily loaded high speed applications.

- Examine the deterministic tribological behavior within the contact to explore the underlying mechanism that governs the role of micro-dimples in the EHL, given the fundamental physics of the micro-dimple behavior has been 
missing in most of the phenomenological experimental works $[5,7-10,23$ -

27, 32, 33].

\subsection{Thesis Outline}

The outline of this thesis is listed below:

- Chapter 2: The governing formulations of the thermal mixed elastohydrodynamic lubrication for a ball-on-disk contact will be introduced. The numerical procedure of will be discussed.

- Chapter 3: Considering a ball-on-disk contact problem, the matrix for a parametric simulation study will be constructed. The simulation results will be documented and discussed.

- Chapter 4: The research activity will be summarized. Conclusions and recommendations for future work will be provided. 


\section{CHAPTER 2}

\section{A THERMAL MIXED EHL MODEL FOR POINT CONTACTS}

\subsection{Governing Formulations}

For a non-conformal point contact of rough surfaces, the thin film hydrodynamic fluid flow within the EHL channel follows the transient two-dimensional (2D) Reynolds equation of [14-16]

$$
\frac{\partial}{\partial x}\left(f_{x} \frac{\partial p}{\partial x}\right)+\frac{\partial}{\partial y}\left(f_{y} \frac{\partial p}{\partial y}\right)=u_{r} \frac{\partial(\rho h)}{\partial x}+\frac{\partial(\rho h)}{\partial t}
$$

where, the coordinate system is set such that the $x$ axis points in the rolling and sliding direction, and the $y$ axis is parallel to the rotation axis of the contact elements. As the contact surfaces of body 1 and body 2 move at the surface tangential velocities of $u_{1}$ and $u_{2}$, the lubricant is entrained into the contact zone at the rate of $u_{r}$, which is usually referred as the rolling or entraining velocity, and is defined as $u_{r}=\frac{1}{2}\left(u_{1}+u_{2}\right)$. In the process, a pressurized hydrodynamic lubrication film with the thickness $h$ and pressure $p$ is established. Considering the contact between rough surfaces, the steady state condition cannot be reached owing to the transient roughness profiles that bounds the EHL flow. 
The time dependent squeeze term [last term on the right hand side of Eq. (1)] is thus included, where $\rho$ represents the lubricant density and $t$ represents time. Under the circumstance of high sliding, the non-Newtonian shear thinning of the lubrication film is expected. Such effect is included through the flow coefficients of $f_{x}$ and $f_{y}$ in Eq. (1).

Assuming an Eyring fluid, whose characteristic reference stress is $\tau_{0}$, these coefficients take the forms of $[14,15]$

$$
f_{x}=\frac{\rho h^{3}}{12 \eta} \cosh \left(\frac{\tau_{m}}{\tau_{0}}\right), \quad f_{y}=\frac{\rho h^{3}}{12 \eta} \frac{\tau_{0}}{\tau_{m}} \sinh \left(\frac{\tau_{m}}{\tau_{0}}\right)
$$

where, $\eta$ is the lubricant viscosity, and $\tau_{m}$ is the mean viscous shear stress that has the expression of $\tau_{m}=-\tau_{0} \sinh ^{-1}\left[\eta u_{s} /\left(\tau_{0} h\right)\right]$, in which, $u_{s}$ represents the sliding velocity and $u_{s}=u_{1}-u_{2}$

Because of the significant surface roughness irregularities of the mechanical elements such as gears, the full film lubrication condition where the contact surfaces are completely separated by the protective fluid film, is hardly achievable. When, for instance, the circumstance of insufficient rolling velocity and/or high lubricant temperature that reduces the lubricant viscosity and consequently the film thickness is encountered, frequent local asperity contacts take place within the contact zone. At these local asperity interaction spots, the film thickness is considered to be constant (infinitesimally small, i.e. $h \approx 0$ ), and the film thickness gradient along the $x$ direction becomes zero as

$$
\frac{\partial h}{\partial x}=0
$$

Such a treatment allows a unified numerical system to be arrived [16], offering superior numerical stability. 
Within the EHL contact zone, the local film thickness at position $(x, y)$ and time $t$ is determined by the local curvature gap, $g_{0}(x, y)$ the local instantaneous roughness heights of surface $1, S_{1}(x, y, t)$ and surface $2, S_{2}(x, y, t)$, and the surface deflection of $V(x, y, t)$ as [14-16]

$$
h(x, y, t)=h_{0}(t)+g_{0}(x, y)+V(x, y, t)-S_{1}(x, y, t)-S_{2}(x, y, t)
$$

where, $h_{0}$ is the reference film thickness, whose value is determined by enforcing the equilibrium condition between the normal load, $W$ and the resultant contact pressure distribution over the entire EHL contact zone of

$$
W=\iint_{\Gamma} p(x, y, t) d x d y
$$

through an iterative adjustment of $h_{0}$. Under the elastic contact condition, the surface deflection is the convolution between the contact pressure and the influence function $K=2 /\left(\pi E^{\prime} \sqrt{x^{2}+y^{2}}\right)$ as $V=\iint_{\Gamma} K\left(x-x^{\prime}, y-y^{\prime}\right) p\left(x^{\prime}, y^{\prime}, t\right) d x^{\prime} d y^{\prime}$ [35]. Here, $E^{\prime}$ represents the reduced elastic modulus, and $\Gamma$ represents the computational domain.

For the determination of the temperature distribution, $T_{f}$ within the EHL fluid, who has the thermal conductivity of $k_{f}$ and the specific heat of $c_{f}$, the energy equation of

$$
k_{f} \frac{\partial^{2} T_{f}}{\partial z^{2}}+\tau \dot{\gamma}=\rho c_{f}\left(u \frac{\partial T_{f}}{\partial x}+\frac{\partial T_{f}}{\partial t}\right)
$$

is applied $[14,15]$. In Eq. $(6), \tau$ and $\dot{\gamma}$ represent the shear stress and the shear strain rate of the fluid, $u$ is the fluid velocity that varies along the $z$ axis, which points from surface 1 to surface 2 across the film thickness, in a linear manner as 


$$
u=u_{1} \frac{h-z}{h}+u_{2} \frac{z}{h}
$$

In order to reduce the degree-of-freedom of Eq. (6), the variation of $T_{f}$ along the $z$ axis is assumed to follow the parabolic form [36]

$$
T_{f}=\left(3 T_{1}+3 T_{2}-6 T_{m}\right)\left(\frac{z}{h}\right)^{2}-\left(4 T_{1}+2 T_{2}-6 T_{m}\right) \frac{z}{h}+T_{1}
$$

where $T_{m}$ is the mean temperature of the fluid across the film thickness, and $T_{i}(i=1,2)$ is the surface temperature of the bounding solid $i$, which is the sum of the surface bulk temperature, $T_{i}^{b}$ and the flash temperature rise, $\Delta T_{i}$ i.e.

$$
T_{i}=T_{i}^{b}+\Delta T_{i}
$$

Considering solid $i$ that is exposed to the heat flux $Q_{i}$, the surface flash temperature rises according to [37]

$$
\Delta T_{i}(x, y, t)=\int_{t} d t^{\prime} \int_{\Gamma} \exp \left\{-\frac{\left[\left(x-x^{\prime}\right)-u_{i}\left(t-t^{\prime}\right)\right]^{2}+\left(y-y^{\prime}\right)^{2}}{4 \kappa_{s}\left(t-t^{\prime}\right)}\right\} \frac{Q_{i}\left(x^{\prime}, y^{\prime}, t^{\prime}\right) d x^{\prime} d y^{\prime}}{4 \rho_{s} c_{S}\left[\pi \kappa\left(t-t^{\prime}\right)\right]^{3 / 2}}(10)
$$

where, $\kappa_{s}$ is the thermal diffusivity, $c_{s}$ the specific heat, and $\rho_{s}$ is density of the solid. The heat fluxes of the mating surfaces are determined through a heat partition coefficient $\vartheta$ as

$$
Q_{1}=\vartheta Q, \quad Q_{2}=(1-\vartheta) Q
$$

where, $\vartheta$ satisfies the boundary condition of $[14,15]$

$$
T_{1}-T_{2}=\frac{h}{2 k_{f}}(1-2 \vartheta) Q
$$


and the total frictional heat flux, $Q$ is the product of the sliding velocity and the shear stress, $q$ as

$$
Q(x, y, t)=u_{s} q(x, y, t)
$$

Within the hydrodynamic areas of the EHL contact zone, $q$ is attributed to the lubricant viscous shear as $q=\eta^{*} u_{S} / h$, where $\eta^{*}$ is the effective viscosity and $\eta^{*}=\eta / \cosh \left(\tau_{m} / \tau_{0}\right)$ for an Eyring fluid. For the local areas where the film thickness breaks down to allow the asperity interaction, $q=\mu_{b} p$ where $\mu_{b}$ is the boundary lubrication friction coefficient, and is assumed to take the value of $0.1[1-3,14-16]$ in this study. Given the surface shear distribution over the entire contact, the friction coefficient $\mu$ is found as $\mu=\iint_{\Gamma} q d x d y / W$ with $W$ representing the applied normal load.

Regarding the determination of $T_{i}^{b}$ of the contacting surfaces that are required in Eq. (9), the bulk temperature of the disk surface (surface 2) is maintained at the lubricant supply temperature. The ball surface (surface 1) is heated by the frictional heat produced by the contact and cooled through the convection between the ball and ambient air-lubricant mixture. The simple 2D heat transfer formulation proposed by Li et al. [15] is used to determine its bulk temperature. For the descriptions of the pressure and temperature dependences of the lubricant viscosity and density, the relationships employed in Refs. [3, $14,15,38]$ are implemented in this study. 


\subsection{Numerical Solution Procedures}

The numerical method for the point contact thermal mixed EHL problem is illustrated in Fig. 2.1. Starting with the guesses of the initial contact pressure (Hertzian) and the initial oil temperature (inlet temperature), the surface elastic deformation and film thickness can be determined. According to the film thickness distribution, the asperity contact spots are located and the fluid viscosity and density are computed for the areas where $h>0$. The unified equation system of Eqs. (1-3) is then solved for $p$ over the entire contact zone. The pressure solution is checked for both the load balance convergence and pressure convergence. The converged $p$ and $h$ are used to find the temperature distributions of the bounding surfaces as well as the fluid. A thermal iteration loop is utilized to ensure the temperature distribution convergences. The converged solutions are then used for the initial guesses of the next time step. For the numerical simulation of the point contact, the EHL computational domain is set to have the square shape that has the

dimension of $L=3 a$ in both the $x$ and $y$ directions, where $a$ is the radius of the circular Hertzian zone. The origin of the computational domain is selected such that $-0.625 L \leq x \leq 0.375 L$ and $-0.5 L \leq y \leq 0.5 L$. The mesh size is set to be $\Delta x=2 \mu \mathrm{m}$ and $\Delta y=2 \mu \mathrm{m}$. The time increment of $\Delta t=\Delta x / u_{r}$ is used with $N_{t}=500$ time steps. 


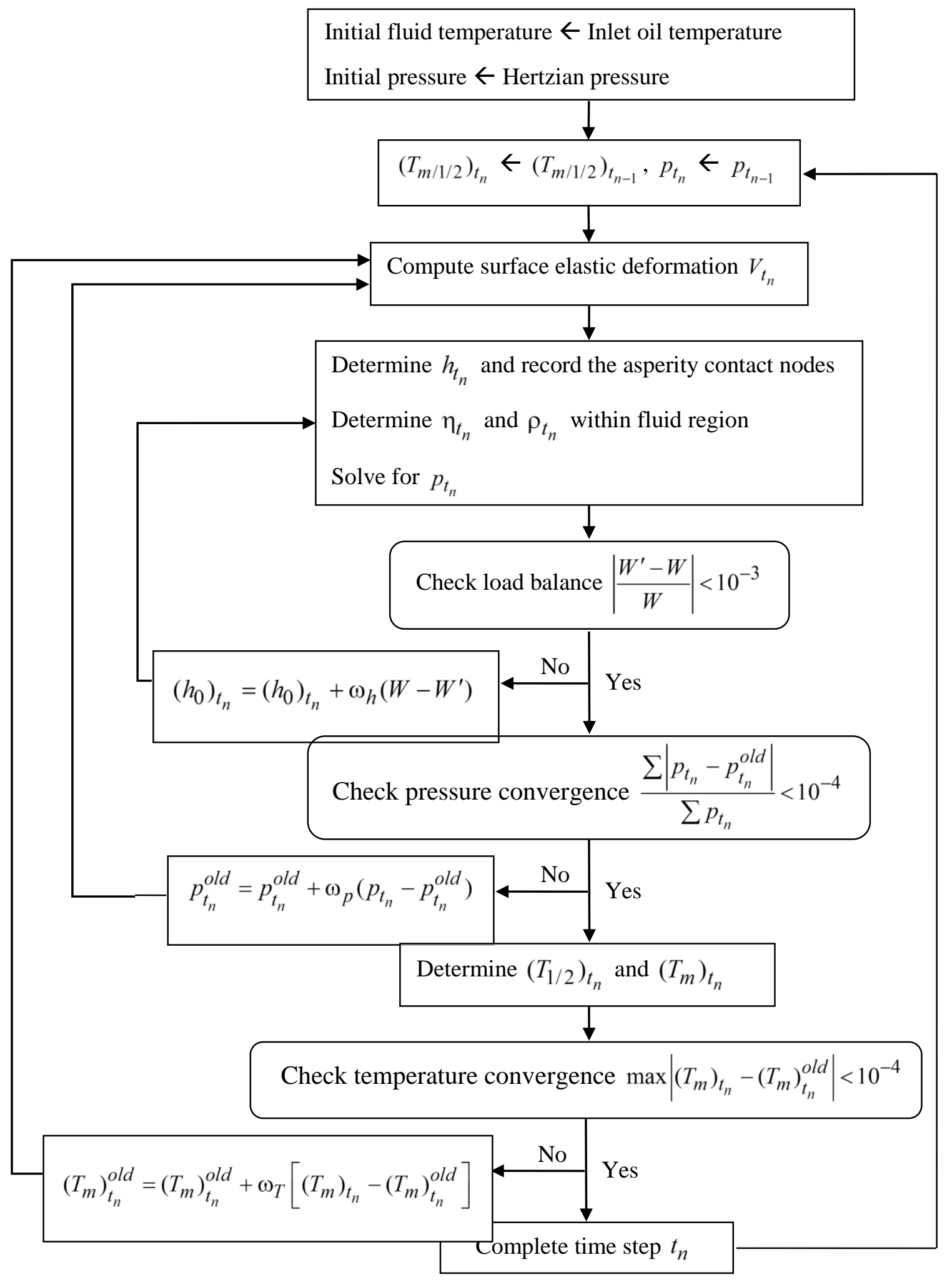

Figure 2-1 Flowchart of the thermal mixed EHL computation. 


\section{CHAPTER 3}

\section{SIMULATIONS AND DISCUSSION}

\subsection{Contact Set-up}

The point contact formed between a circular ball (body 1), whose diameter is 25.4 mm, and a flat disk (body 2) as shown in Fig. 3.1 is considered in this study. The normal force, $W$ applies in the vertical direction and pushes the ball down against the disk. The rotational axis of the ball is set to be along the radial direction of the disk, whose rotational axis while is in the vertical direction, such that the surface velocities of the two contact elements, $u_{1}$ and $u_{2}$, are parallel to each other. Three types of the ball-disk surface texture combinations as listed in Table 3.1 are examined. For the type I combination, the micro-

dimple texturing, which is followed by the isotropic polishing process, is applied onto the ball surface. The dimple array is defined by the radius of the circular dimples, $R$ the depth of the dimples, $H$, and the center distance between the adjacent dimples, $D$ (The center distances in the $x$ and $y$ directions are set to be equal). 


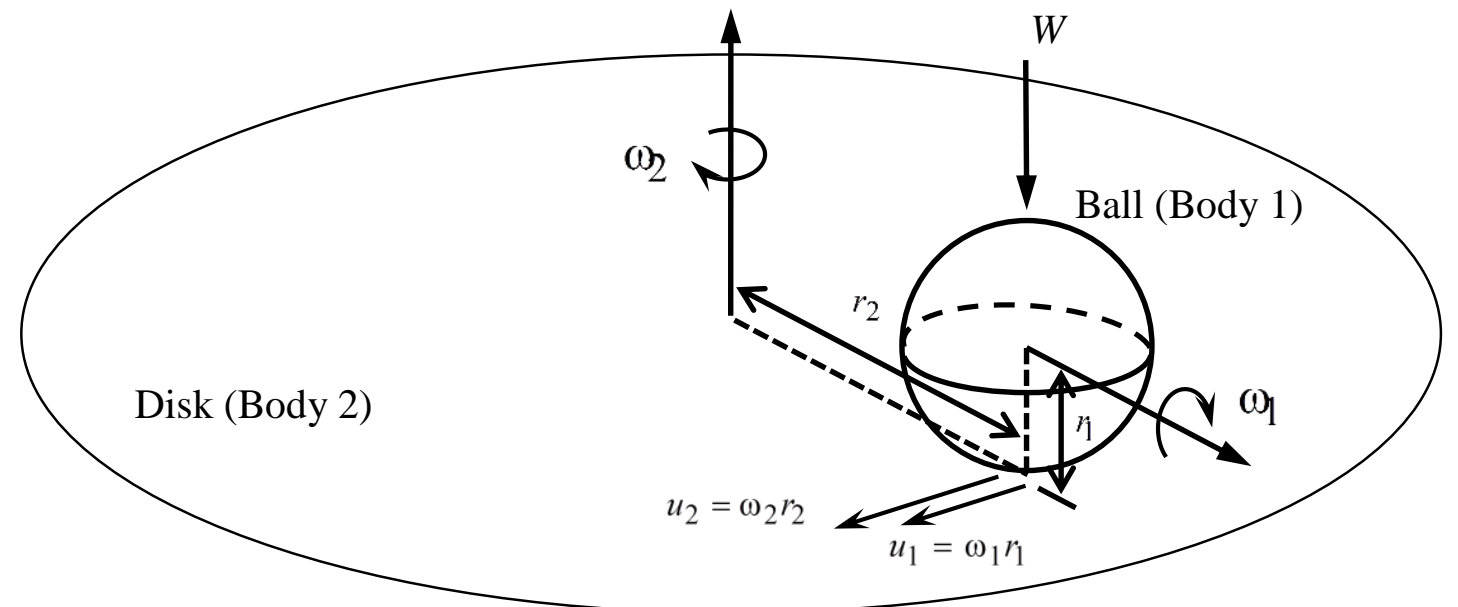

Figure 3-1 The contact set-up between a circular ball and a flat disk 
Table 3-1 List of the surface texture conditions of the contact pair.

\begin{tabular}{ccc}
\hline Surface & & Disk Surface \\
Texture & Ball Surface Texture & Texture \\
Combination & Micro-dimple textured + & Polished \\
I & Polished & Polished \\
II & Ground & Ground \\
III & & \\
\hline
\end{tabular}


Table 3-2 Definition of simulation case numbers for different combinations of dimple depth, $H$ and dimple center distance, $D$

\begin{tabular}{cccc}
\hline & \multicolumn{3}{c}{$D[\mu \mathrm{m}]$} \\
\cline { 2 - 3 } & 90 & 60 & 45 \\
\cline { 2 - 3 } 3 & $H^{b} D^{a}$ & $H^{a} D^{b}$ & $H^{a} D^{c}$ \\
1.5 & $H^{b} D^{b}$ & $H^{b} D^{c}$ \\
15 & $H^{c} D^{a}$ & $H^{c} D^{b}$ & $H^{c} D^{c}$ \\
\hline
\end{tabular}


(a)

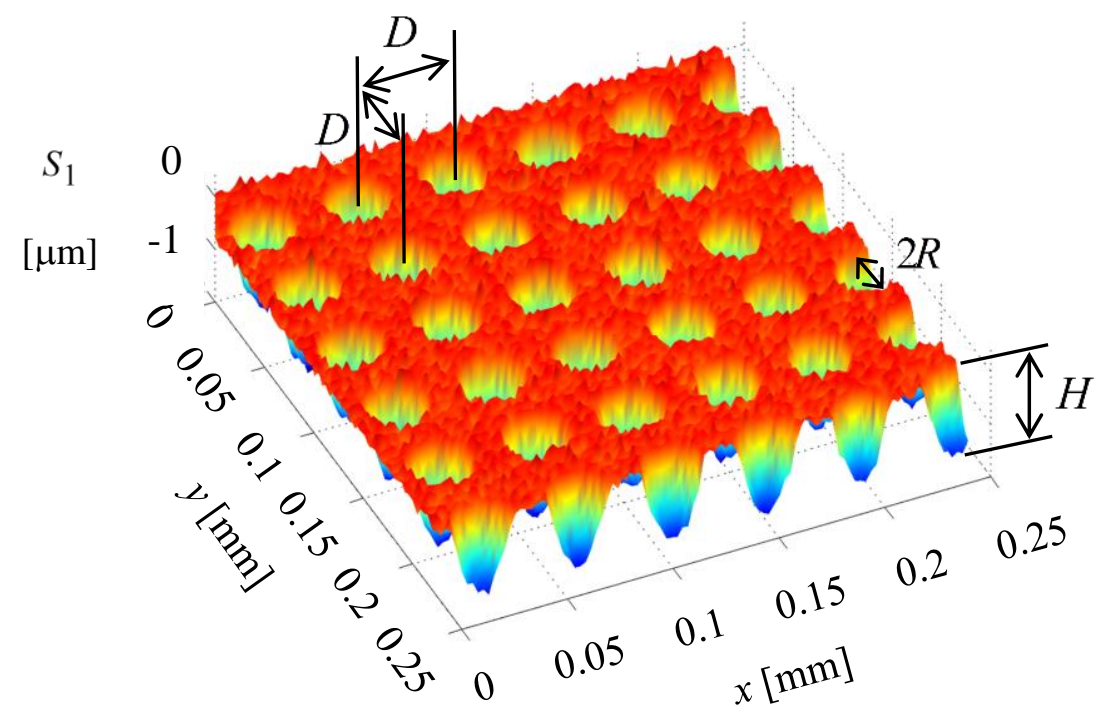

(b)

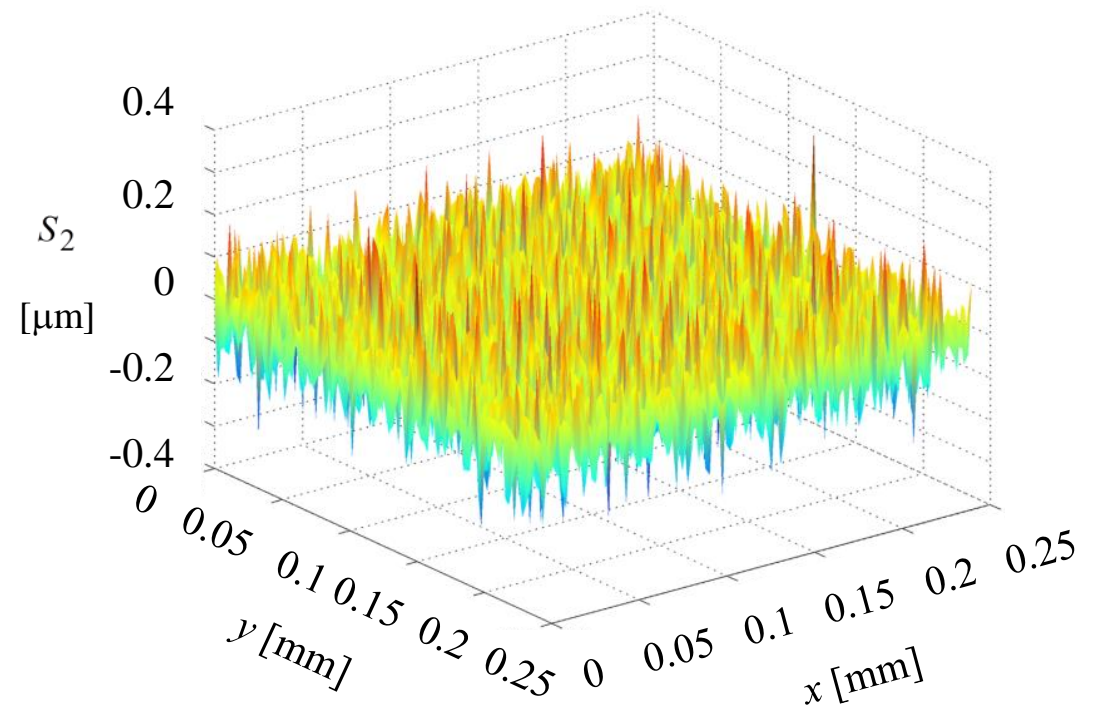

Figure 3-2 The surface topographies of (a) ball specimen and (b) disk specimen for the type I surface texture combination defined in Table 3.1 
To investigate the impacts of $H$ and $D$ on the tribological behavior of the point contact, three depth values $H=1.5,3$ and $15 \mu \mathrm{m}$, and three center distance values $D=45$ , 60 and $90 \mu \mathrm{m}$ as listed in Table 3.2 are considered, keeping the dimple radius fixed at $R=15 \mu \mathrm{m}$. No micro-dimples are produced on the disk surface that is isotropically polished only. Figure 3.2 shows the surface topography of the ball and disk specimens of the type I surface texture combination, where the example dimple array has $H=1.5 \mu \mathrm{m}$ and $D=45 \mu \mathrm{m}$. The ball surface between the dimples and the disk surface have the rootmean-square (RMS) roughness amplitude $R_{q}=0.1 \mu \mathrm{m}$. Neither the type II nor the type III surface texture combination possesses the micro-dimple feature. The type II combination has both the ball and the disk surfaces isotropically polished only, resulting in the surface topography that is similar to Fig. 3.2 (b). The type III contact pair consists of a ground ball surface and a ground disk surface, providing a rougher surface condition with the RMS roughness amplitude $R_{q}=0.6 \mu \mathrm{m}$ as shown in Fig. 3.3. It is observed the roughness lay of the ground surface is oriented in the $y$ direction, i.e. is normal to the rolling and sliding direction of the contact elements. This set-up imitates the contact condition of gears.

\subsection{Operating Conditions}

Three rolling velocities of $u_{r}=0.5,5$, and $10 \mathrm{~m} / \mathrm{s}$ are employed. The slide-to-roll ratio that is defined as $S R=u_{S} / u_{r}$ is fixed at $S R=-0.5$ for all the simulations, where the negative sign indicates the ball surface moves slower than the disk surface does. In the vicinity of this sliding condition, the failures such as pitting and scuffing are commonly 


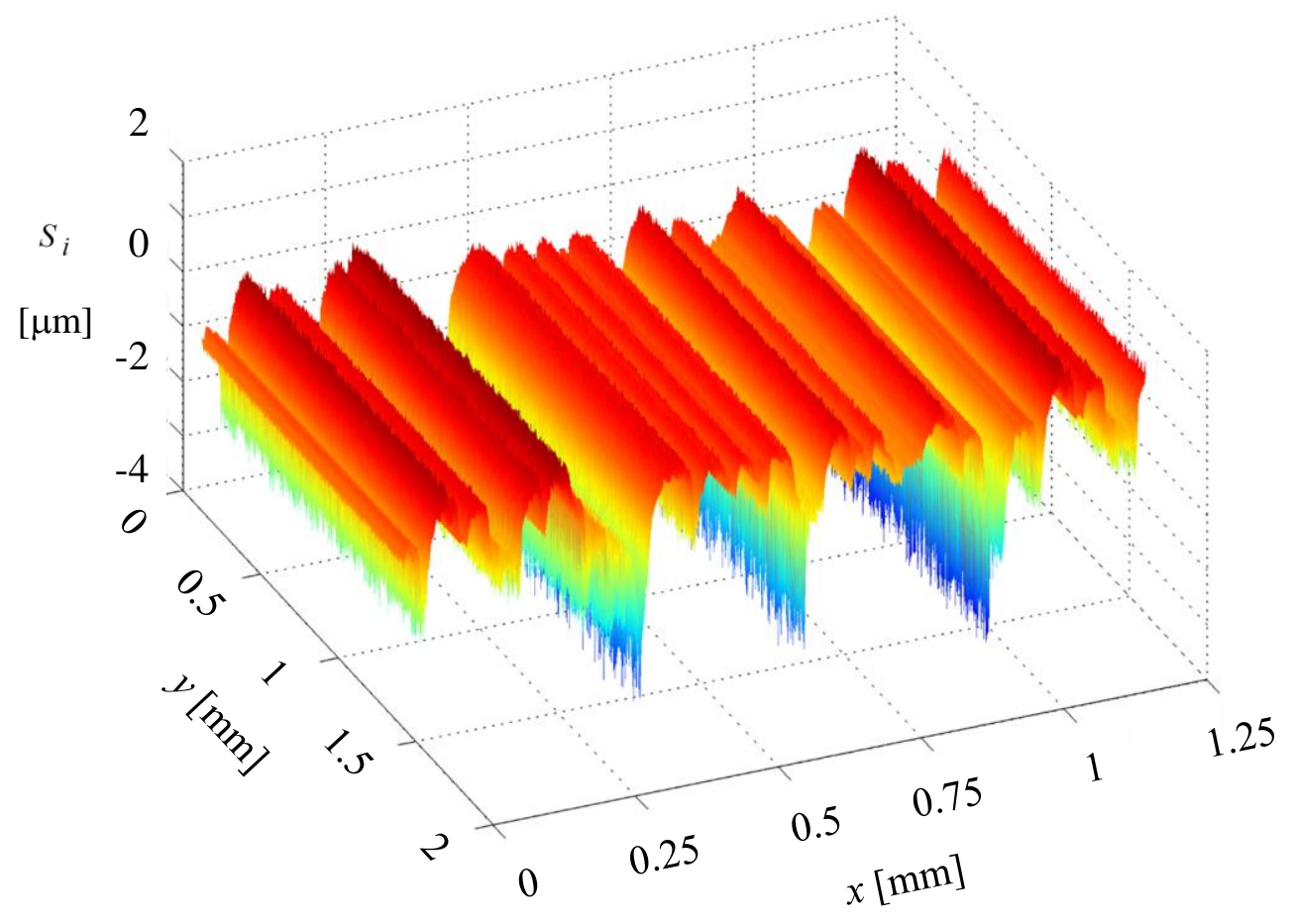

Figure 3-3 The surface topography of the ground surface. 


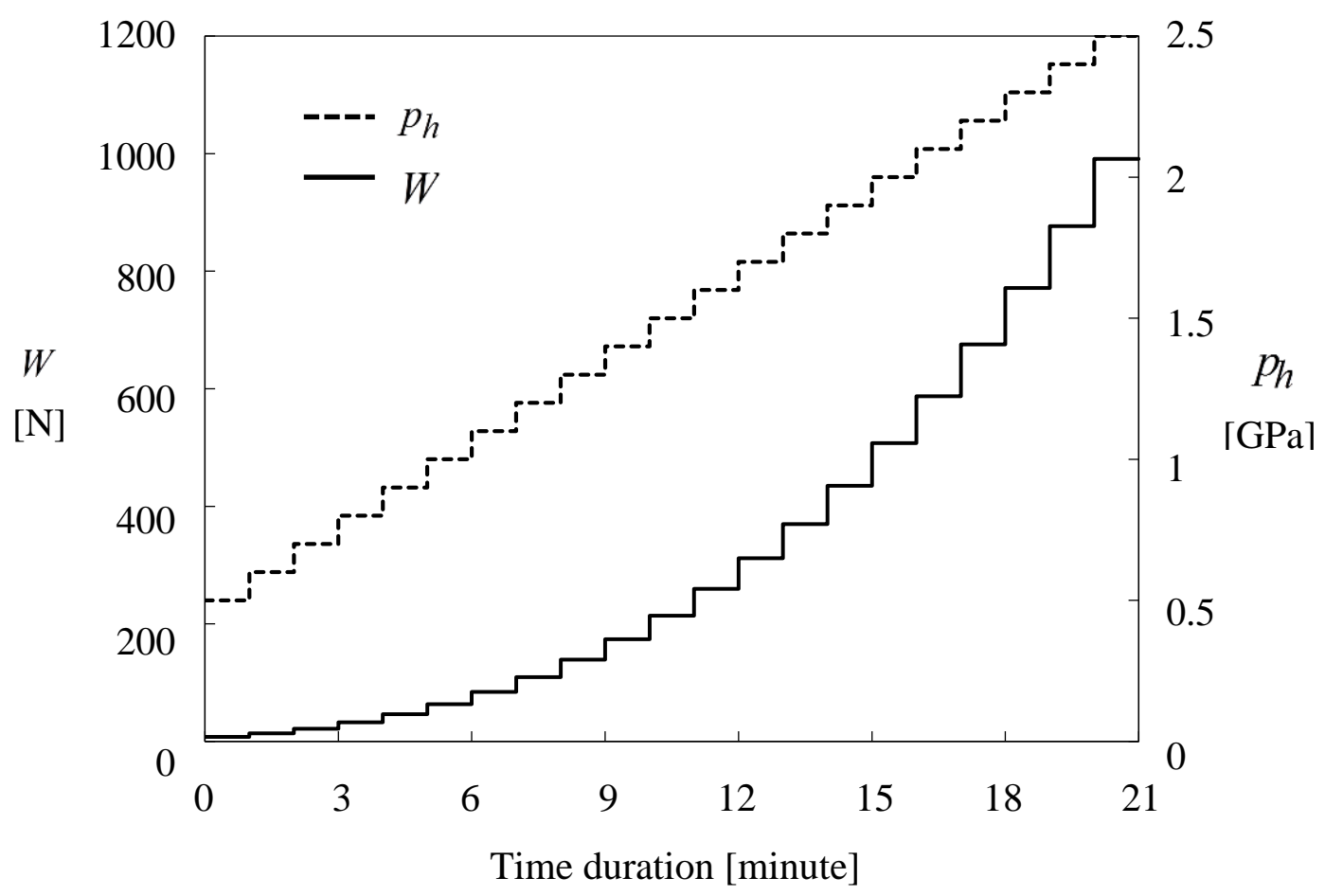

Figure 3-4 The variations of $W$ and $p_{h}$ with time for one complete ball-on-disk contact simulation. 
observed for gearing applications. For one complete simulation, the normal load in terms of the maximum Hertzian pressure, $p_{h}$, is increased stepwise from 0.5 to $2.5 \mathrm{GPa}$ with the increment of 0.1 GPa as shown in Fig. 3.4. The corresponding normal force, $W$, that varies in the range from 7.95 to $990.9 \mathrm{~N}$ is also plotted in the figure. Each of these loading stages has the operating time duration of one minute. For the lubrication of this ball-on-disk contact, a typical turbine fluid, MIL-L23699, is used as the lubricant, whose inlet temperature is set at $100{ }^{\circ} \mathrm{C}$. The detailed viscosity and density parameters of this lubricant is referred to Ref. [39]. During the contact, the bulk temperature of the disk is controlled and maintained at the lubricant inlet temperature, i.e. $T_{2}^{b}=100{ }^{\circ} \mathrm{C}$, while the ball bulk temperature varies according to the frictional heat produced within the contact [Eq. (13)], the heat convection between the ball surface and the surrounding air, and the operating time period. The $2 \mathrm{D}$ heat transfer model that was proposed by Li et al. [15] is adopted here to determine $T_{1}^{b}$.

\subsection{Simulation Results}

Operating at the rolling velocity $u_{r}=10 \mathrm{~m} / \mathrm{s}$ and at the highest loading stage where $p_{h}=2.5 \mathrm{GPa}$, the tribological behavior of the ball-disk contact pair, which has the type I

surface texture combination (defined in Table 3.1) and Case $H^{a} D^{a}$ micro-dimple array ( $H=1.5 \mu \mathrm{m}$ and $D=90 \mu \mathrm{m}$ in Table 3.2), is depicted in Fig. 3.5 for one example time instant. In Fig. 3.5 (a), the local asperity contacts are represented by the black areas. Within the left half of the Hertzian zone $(x<0)$, the asperity contact activities are seen to be more 
frequent in comparing to the right half of the Hertzian zone $(x>0)$, especially along the circumferences of the dimples. At these asperity interaction spots, the contact pressures are elevated to very high magnitudes as shown in Fig. 3.5 (b). Within the right half of the Hertzian zone, the hydrodynamic fluid film dominates and the hydrodynamic pressure is observed to be severe at the right edges of the dimples in Fig. 3.5 (b), owing to the microEHD behavior, i.e. the dimples serve as micro-bearings when the disk surface slides against the roller surface to the right. In addition, pressure tails are produced to the right of these dimples. This phenomenon is in good agreement with the optical interferometry measurements of Wedeven and Cusano [40] and Cusano and Wedeven [41]. The high pressure peaks within the contact not only dictate the surface fatigue crack nucleation, but also introduce high frictional heat to promote the flash temperature rise. In Fig. 3.5 (c), the lubrication fluid temperature reaches as high as $350{ }^{\circ} \mathrm{C}$ in the areas where the hydrodynamic pressure takes the local maximum. The ball surface in Fig. 3.5 (d) has its temperature approaching $250^{\circ} \mathrm{C}$, where either the asperity contact pressure or the hydrodynamic pressure peaks locally. These extreme temperatures are responsible for the surface welding and consequently the onset of the scuffing failure [15].

Owing to the time-varying surface topographies of the ball and the disk when they rotate, the tribological behavior in Fig.3.5 is time dependent. To include such variation in the quantification of the friction and temperature performances, the means of the friction coefficient and the maximum ball surface temperature over $N_{t}$ time instants $\left(N_{t}=300\right.$ in this study) are defined as 


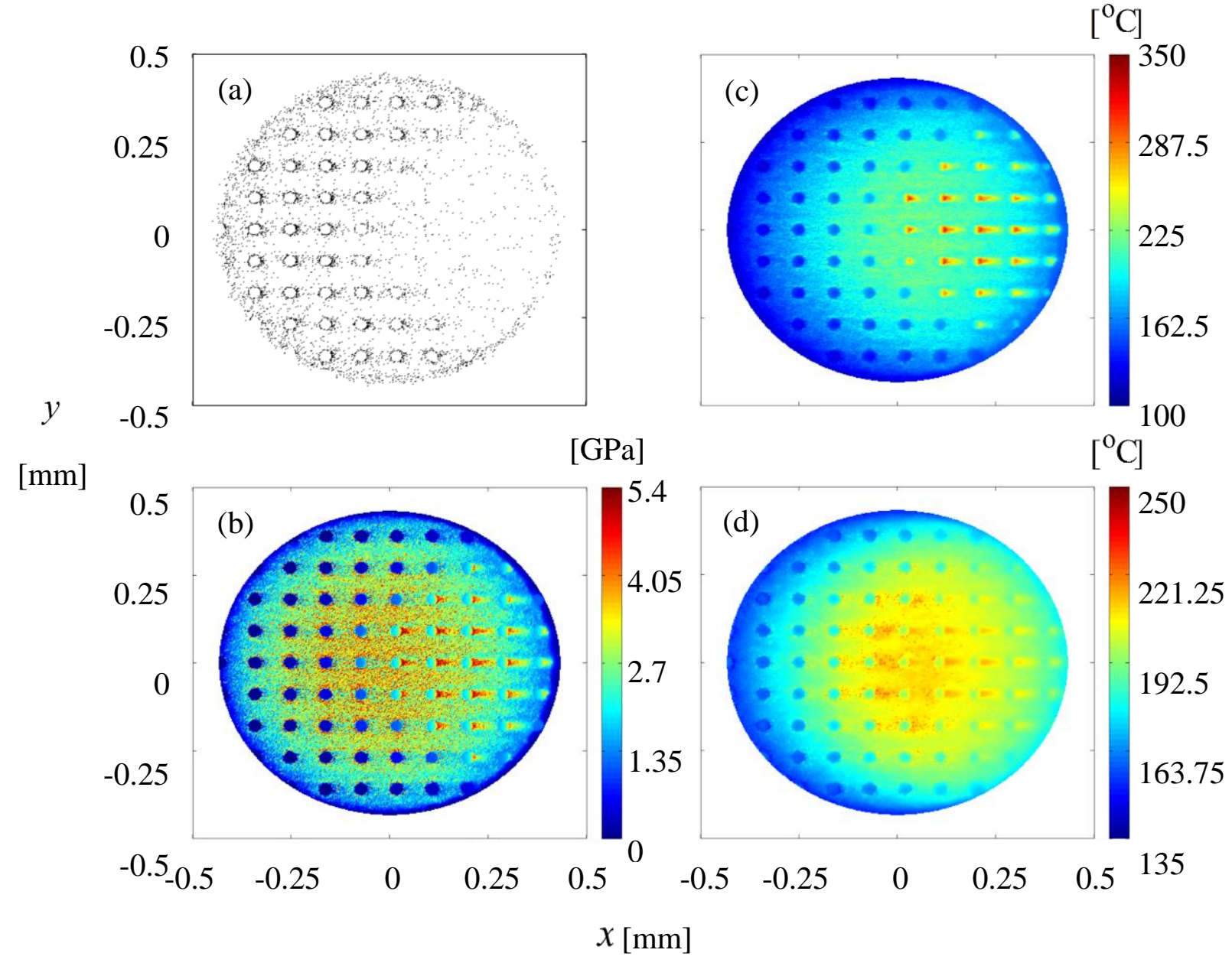

Figure 3-5 The distributions of (a) asperity contacts, (b) contact pressure, (c) lubricant temperature and (d) ball surface temperature within the Hertzian zone. The surface texture combination is Type I of Table 3.1. The micro-dimple array is Case $H^{a} D^{a}$ of Table 3.2. $u_{r}=10 \mathrm{~m} / \mathrm{s}$ and $p_{h}=2.5 \mathrm{GPa}$. 


$$
\bar{\mu}=\frac{1}{N_{t}} \sum_{j=1}^{N_{t}} \mu_{j}
$$

and

$$
\bar{T}_{1}^{\max }=\frac{1}{N_{t}} \sum_{j=1}^{N_{t}}\left\{\max \left[T_{1}(x, y)\right]\right\}_{j}
$$

respectively. Figure 3.6(a) compares $\bar{\mu}$ in Cases $H^{a} D^{a}, H^{a} D^{b}$ and $H^{a} D^{c}$, examining the impact of the dimple center distance, $D$, on the friction of the type I surface texture combination under the rolling velocity $u_{r}=10 \mathrm{~m} / \mathrm{s}$. It is observed $\bar{\mu}$ increases as $D$ decreases $\left(D=90,60\right.$ and $45 \mu \mathrm{m}$ for Cases $H^{a} D^{a}, H^{a} D^{b}$ and $H^{a} D^{c}$, respectively) within the entire loading range $0.5 \leq p_{h} \leq 2.5 \mathrm{GPa}$. This trend is mainly due to two reasons. Firstly, the smaller center distance between the dimples allows to accommodate more dimples within the contact zone, leading to increased asperity contact activity occurring along the circumferences of the dimples, as shown in the left column of Fig. 3.7 under the loading condition of $p_{h}=2.5 \mathrm{GPa}$ for instance. At this loading stage, the asperity contact area ratio that is defined as the ratio of the total asperity contact area to the Hertzian zone area is found to be doubled when the dimple center distance is reduced from 90 to $60 \mu \mathrm{m}$, and tripled when $D$ decreases from 90 to $45 \mu \mathrm{m}$. Secondly, the increased number of the dimples means the increased number of the micro-bearings within the contact, which introduce significant hydrodynamic pressure tails starting from the right edges of the dimples. Both the high asperity contact pressures and the high micro-EHD hydrodynamic pressures as illustrated in the right column of Fig. 3.7 contribute to the increase in the friction coefficient when the dimple center distance is reduced. 

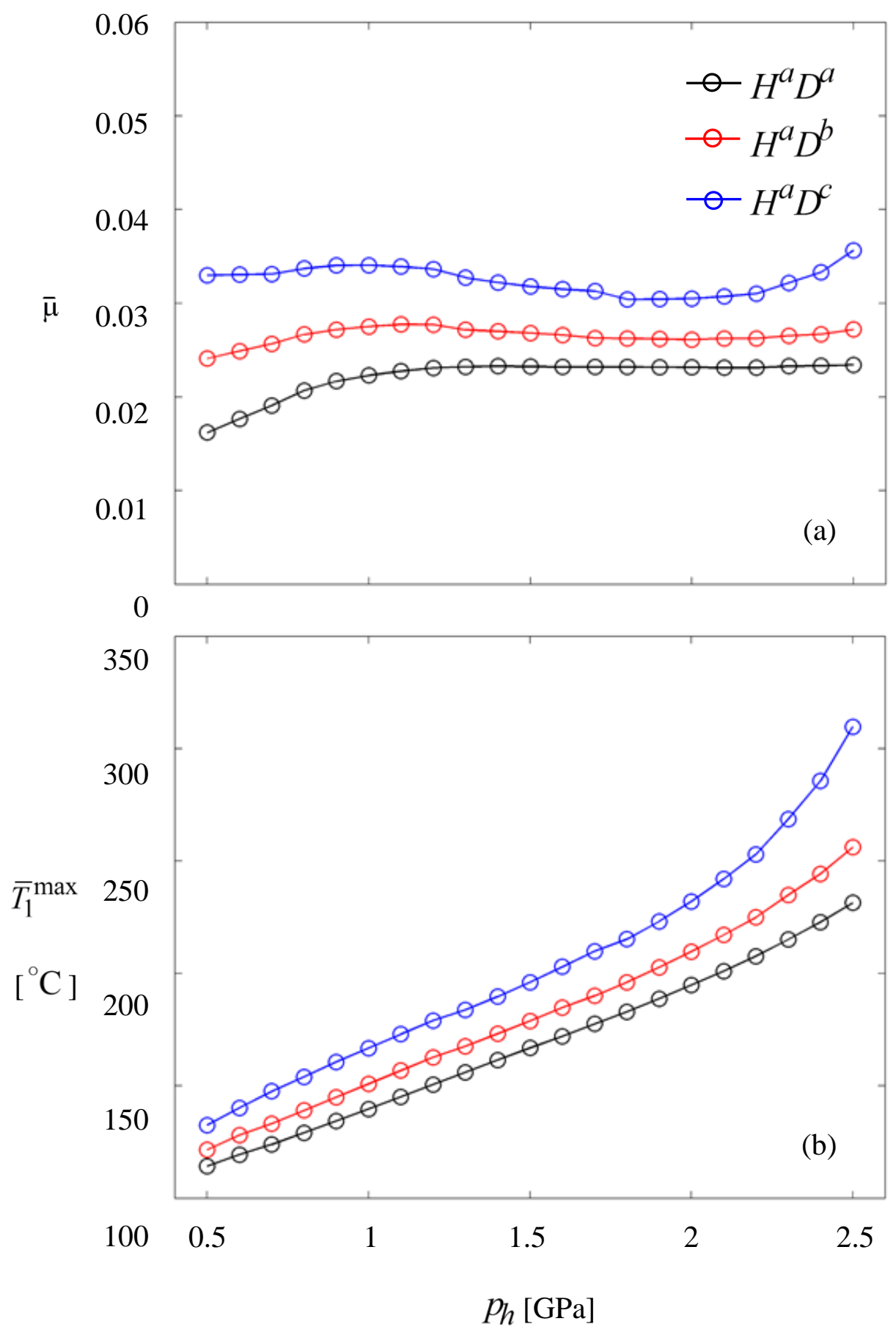

Figure 3-6 The comparisons of (a) $\bar{\mu}$ and (b) $\bar{T}_{1}^{\max }$ between the micro-dimple array Cases $H^{a} D^{a}$, $H^{a} D^{b}$ and $H^{a} D^{c}$ (defined in Table 3.2) for the type I surface texture combination (defined in Table 3.1) under $u_{r}=10 \mathrm{~m} / \mathrm{s}$. 
(a)

[GPa]
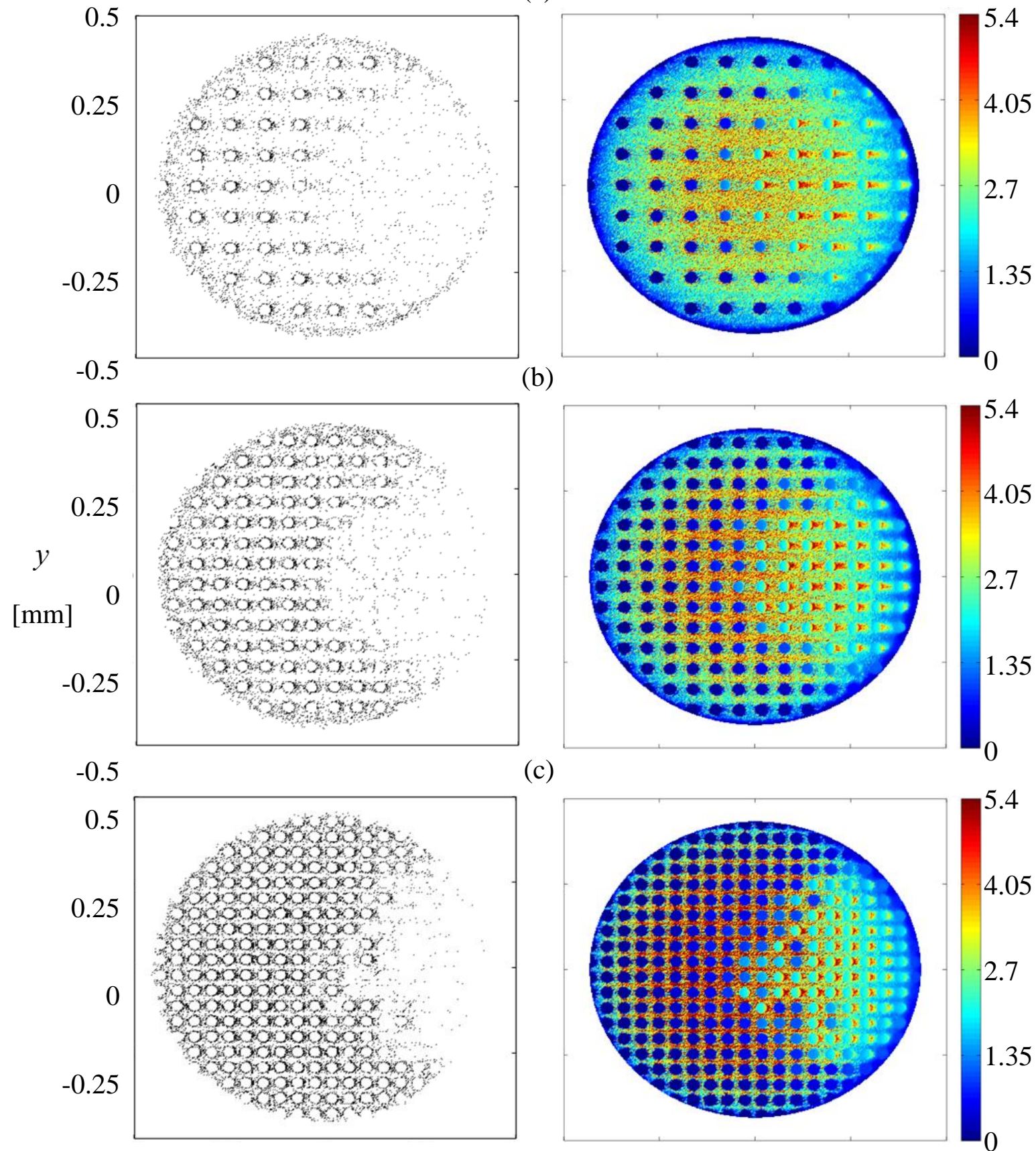

(c)

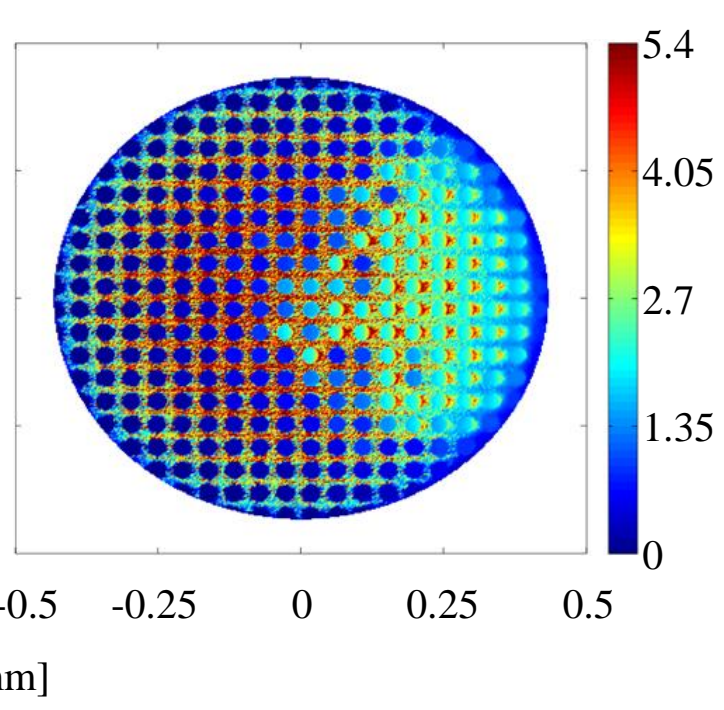

Figure 3-7 The comparison of the asperity contact activity (left column) and the contact pressure (right column) between the micro-dimple array cases (a) $H^{a} D^{a}$, (b) $H^{a} D^{b}$ and (c) $H^{a} D^{c}$ within the Hertzian Zone. The surface texture combination is Type I of Table 3.1. $u_{r}=10 \mathrm{~m} / \mathrm{s}$, and $p_{h}=2.5 \mathrm{GPa}$. 

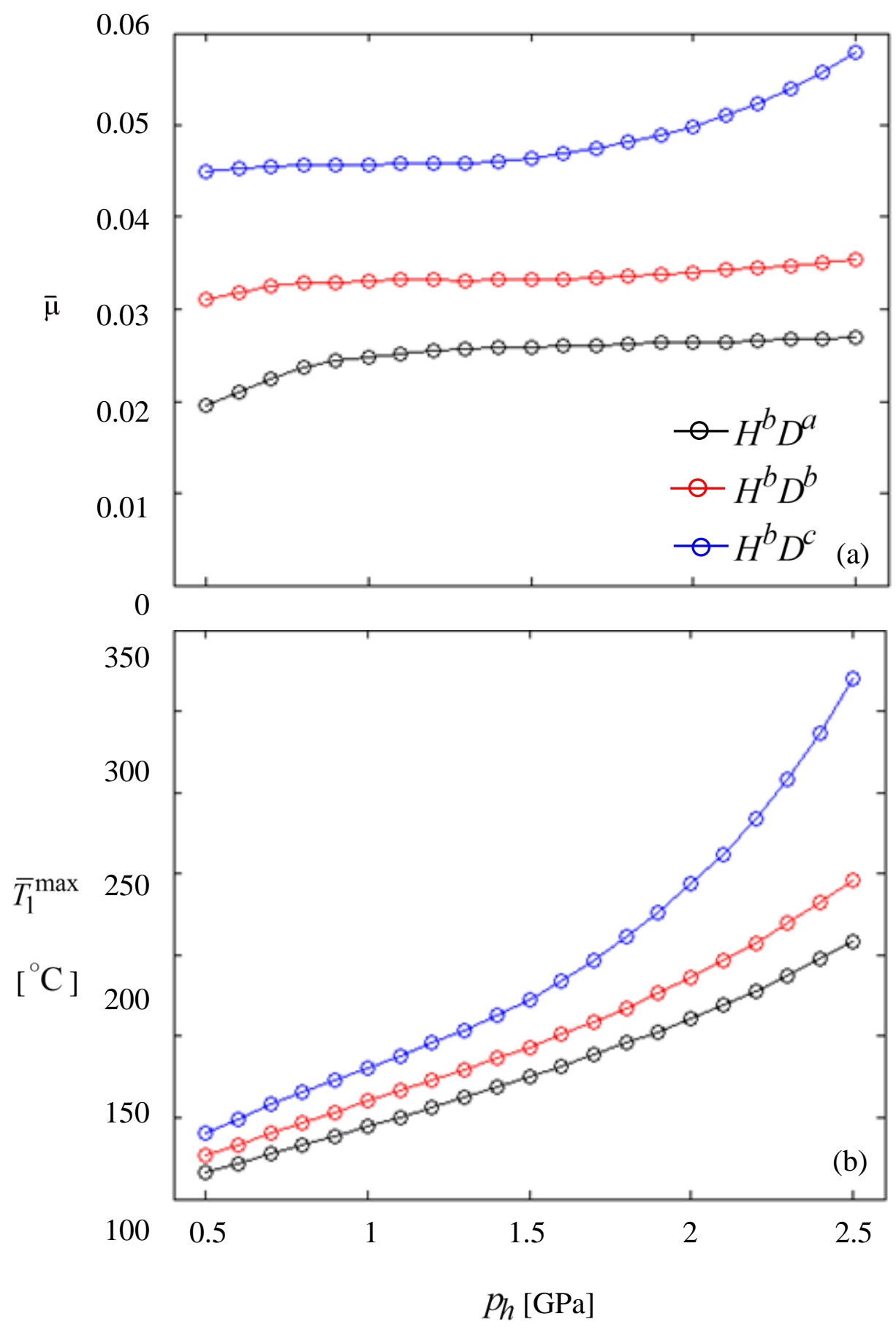

Figure 3-8 The comparisons of (a) $\bar{\mu}$ and (b) $\bar{T}_{1}^{\max }$ between the micro-dimple array Cases $H^{b} D^{a}$, $H^{b} D^{b}$ and $H^{b} D^{c}$ (defined in Table 3.2) for the type I surface texture combination (defined in Table 3.1) under $u_{r}=10 \mathrm{~m} / \mathrm{s}$. 

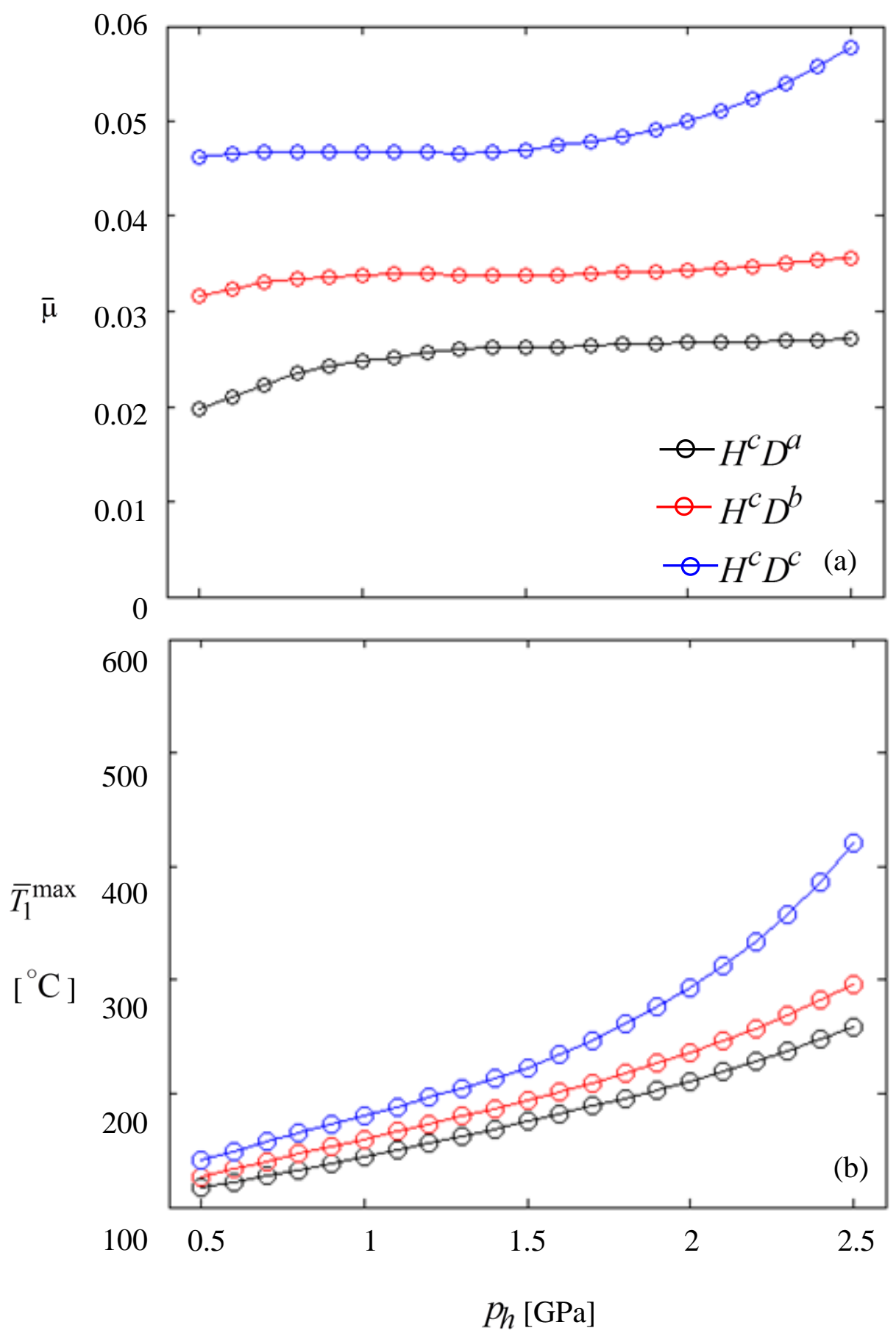

Figure 3-9 The comparisons of (a) $\bar{\mu}$ and (b) $\bar{T}_{1}^{\max }$ between the micro-dimple array Cases $H^{c} D^{a}$, $H^{c} D^{b}$, and $H^{c} D^{c}$ (defined in Table 3.2) for the type I surface texture combination (defined in Table 3.1) under $u_{r}=10 \mathrm{~m} / \mathrm{s}$. 

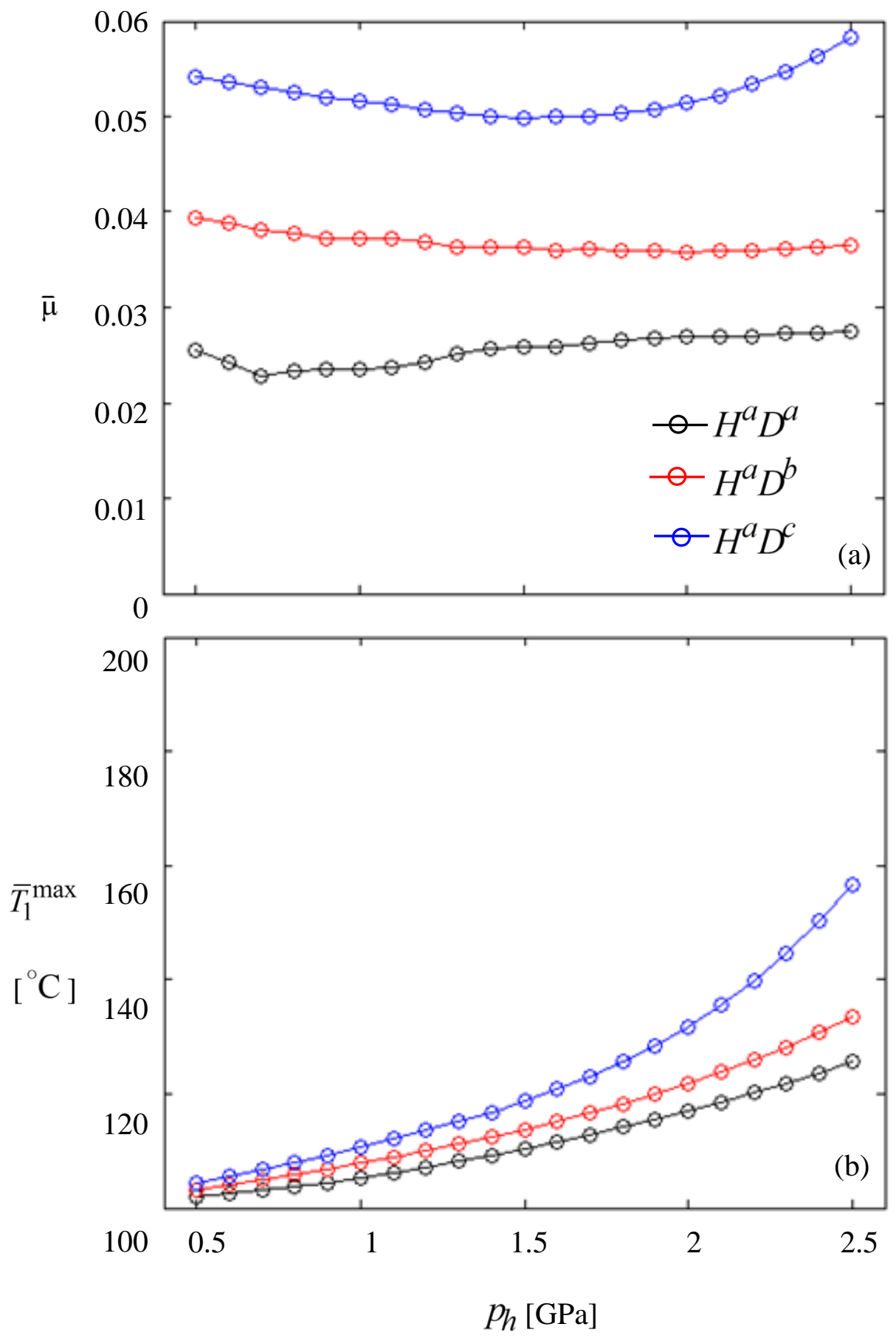

Figure 3-10 The comparisons of (a) $\bar{\mu}$ and (b) $\bar{T}_{1}^{\max }$ between the micro-dimple array Cases $H^{a} D^{a}$, $H^{a} D^{b}$ and $H^{a} D^{c}$ (defined in Table 3.2) for the type I surface texture combination (defined in Table 3.1) under $u_{r}=5 \mathrm{~m} / \mathrm{s}$. 

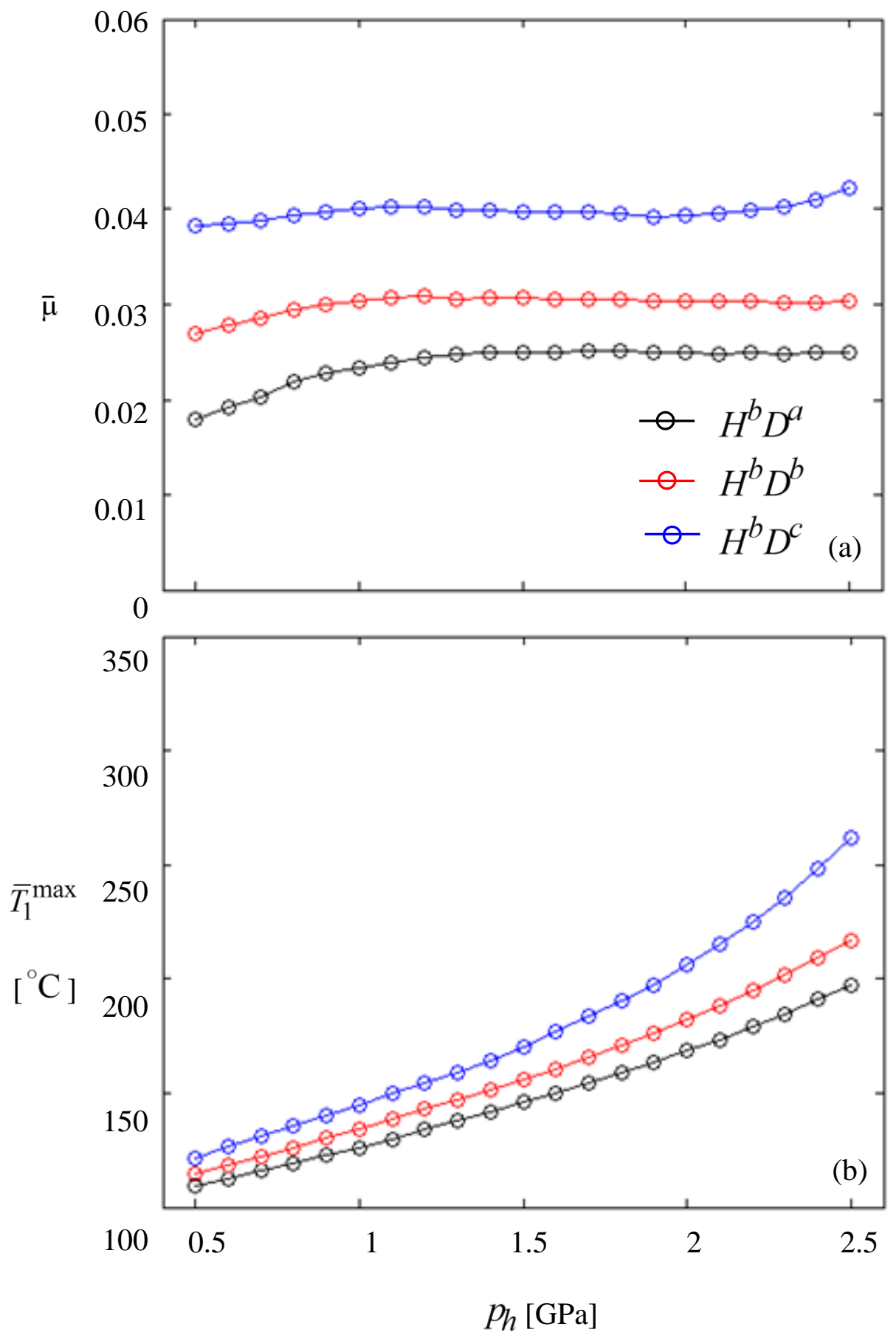

Figure 3-11 The comparisons of (a) $\bar{\mu}$ and (b) $\bar{T}_{1}^{\max }$ between the micro-dimple array Cases $H^{b} D^{a}$, $H^{b} D^{b}$ and $H^{b} D^{c}$ (defined in Table 3.2) for the type I surface texture combination (defined in Table 3.1) under $u_{r}=5 \mathrm{~m} / \mathrm{s}$. 

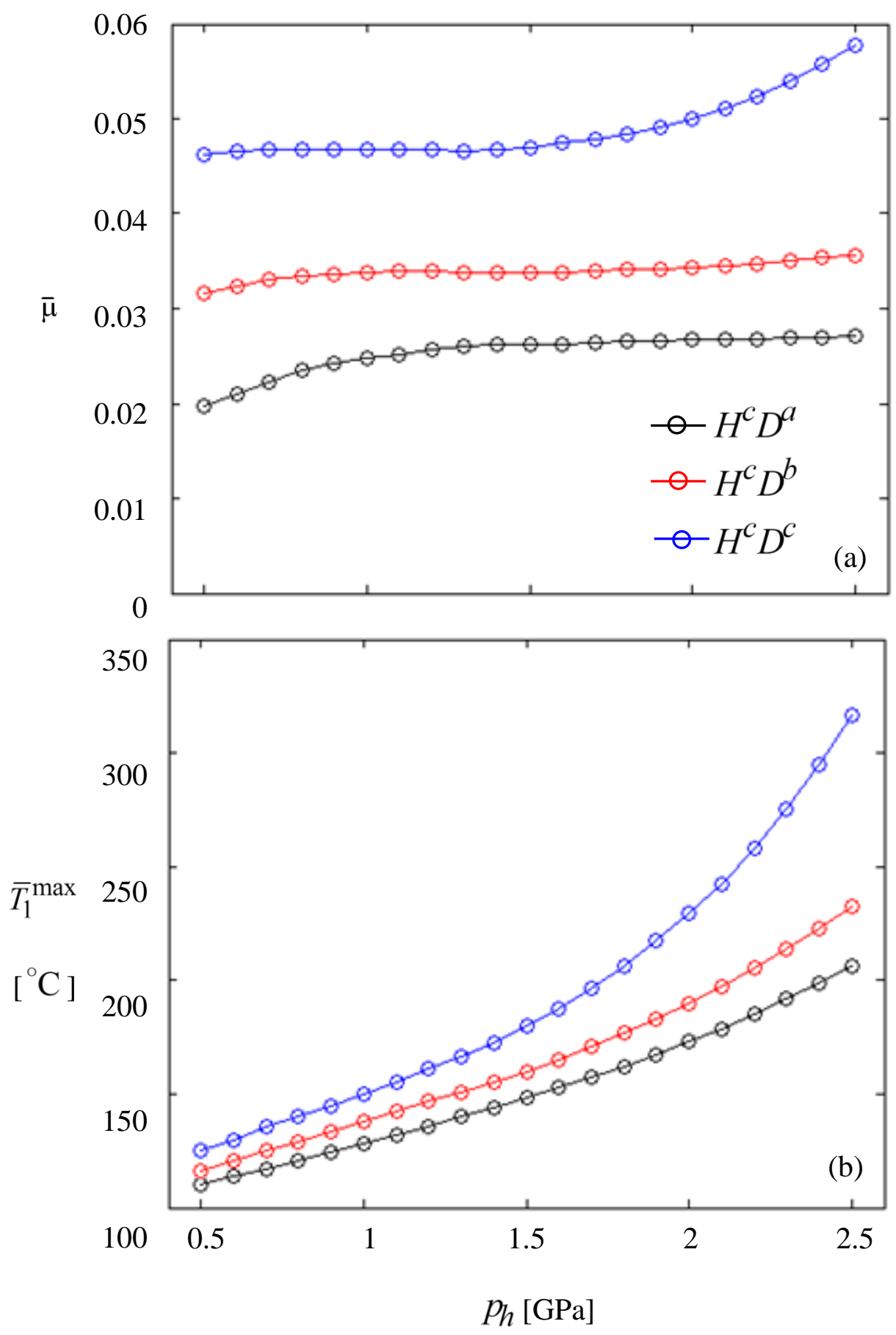

Figure 3-12 The comparisons of (a) $\bar{\mu}$ and (b) $\bar{T}_{1}^{\max }$ between the micro-dimple array Cases $H^{c} D^{a}$, $H^{c} D^{b}$ and $H^{c} D^{c}$ (defined in Table 3.2) for the type I surface texture combination (defined in Table 3.1) under $u_{r}=5 \mathrm{~m} / \mathrm{s}$. 

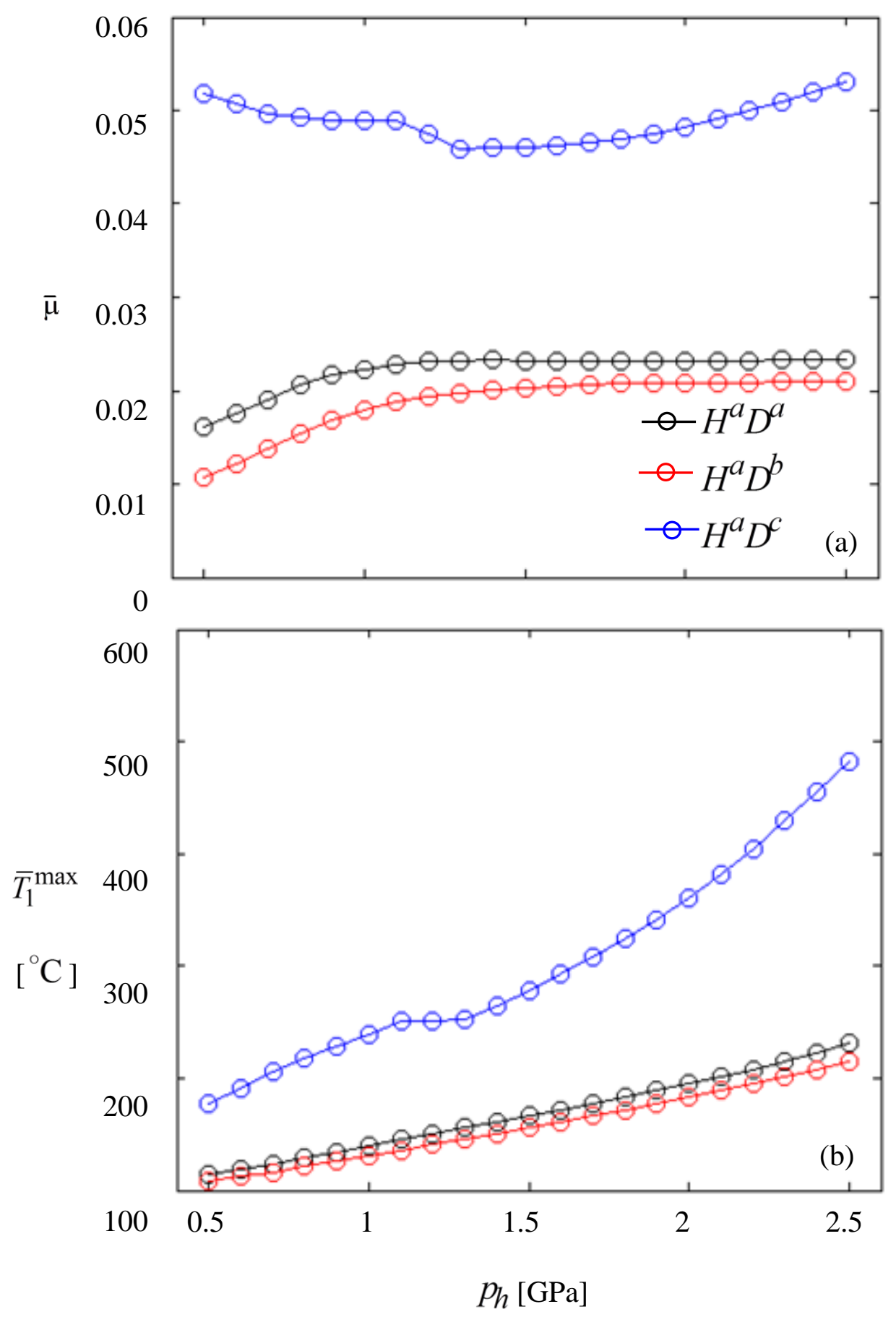

Figure 3-13 The comparisons of (a) $\bar{\mu}$ and (b) $\bar{T}_{1}^{\max }$ between the micro-dimple array Cases $H^{a} D^{a}$, $H^{a} D^{b}$ and $H^{a} D^{c}$ (defined in Table 3.2) for the type I surface texture combination (defined in Table 3.1) under $u_{r}=0.5 \mathrm{~m} / \mathrm{s}$. 

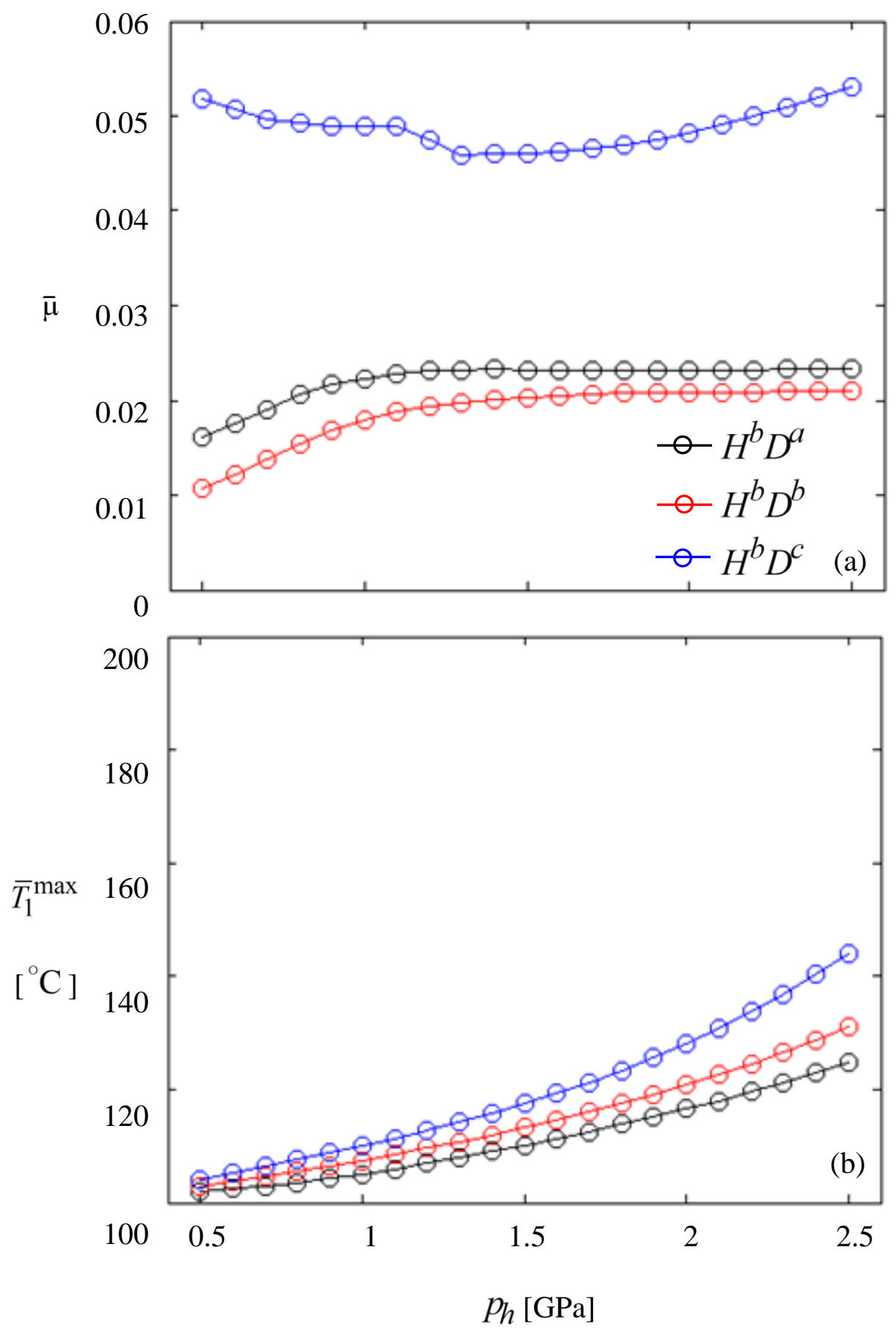

Figure 3-14 The comparisons of (a) $\bar{\mu}$ and (b) $\bar{T}_{1}^{\max }$ between the micro-dimple array Cases $H^{b} D^{a}$, $H^{b} D^{b}$ and $H^{b} D^{c}$ (defined in Table 3.2) for the type I surface texture combination (defined in Table 3.1) under $u_{r}=0.5 \mathrm{~m} / \mathrm{s}$. 

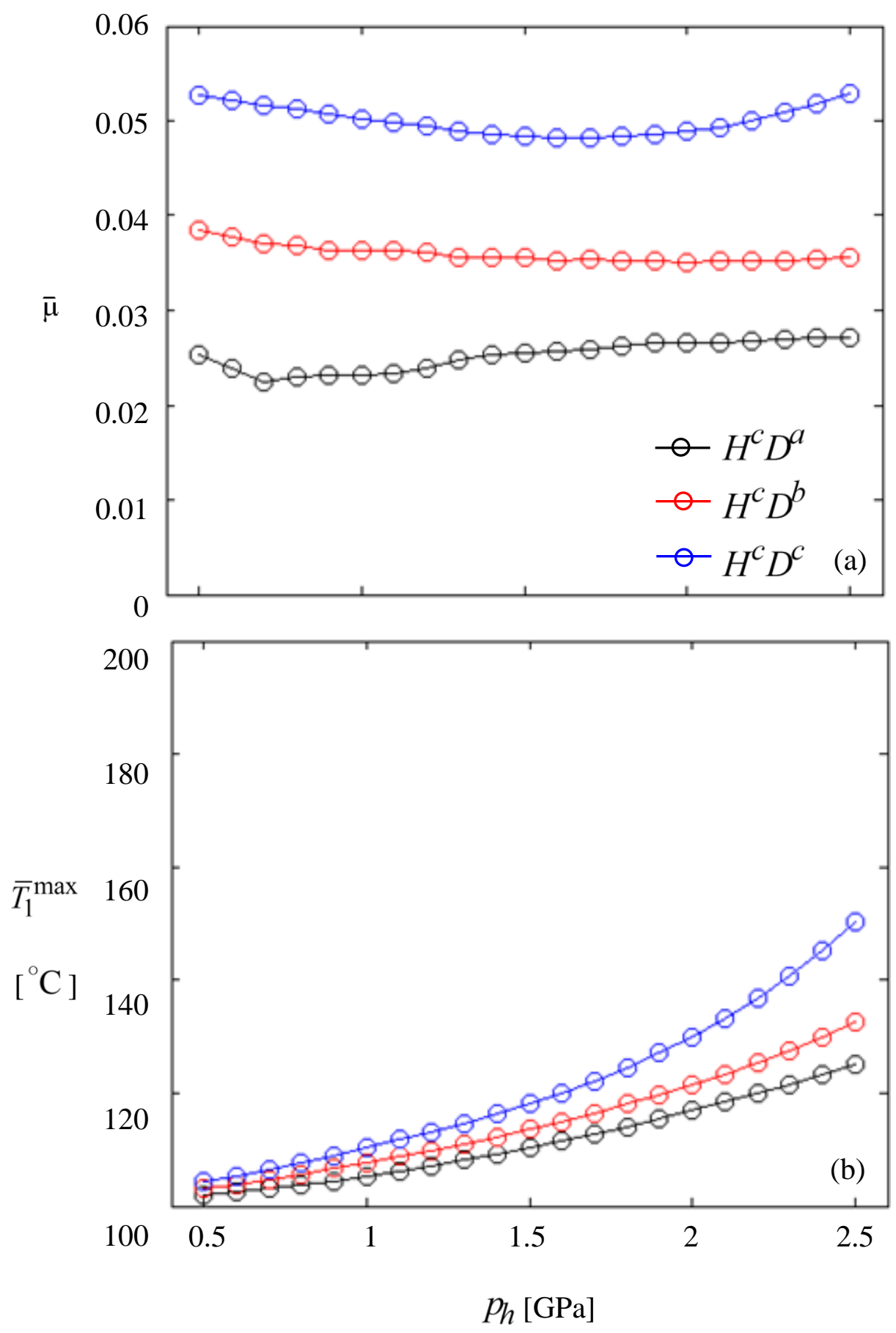

Figure 3-15 The comparisons of (a) $\bar{\mu}$ and (b) $\bar{T}_{1}^{\max }$ between the micro-dimple array Cases $H^{c} D^{a}$, $H^{c} D^{b}$ and $H^{c} D^{c}$ (defined in Table 3.2) for the type I surface texture combination (defined in Table 3.1) under $u_{r}=0.5 \mathrm{~m} / \mathrm{s}$. 
Comparing $\bar{T}_{1}^{\max }$ in Cases $H^{a} D^{a}, H^{a} D^{b}$ and $H^{a} D^{c}$ in Fig. 3.6(b), it is concluded that the smaller the dimple center distance, the higher $\bar{T}_{1}^{\text {max }}$, owing to the increase of the friction when $D$ decreases. The comparisons for the other eight cases defined in Table 3.2 are performed in Figs. 3.8 - 3.15, showing similar observations.

In Fig. 3.16, the contour distributions of $\bar{\mu}$ (left column) and $\bar{T}_{1}^{\max }$ (right column) are constructed versus the dimple center distance and the dimple depth under the lowest loading condition $p_{h}=0.5 \mathrm{GPa}$ for the type I surface texture combination. It is observed that $\bar{\mu}$ increases with the increase of $H$ and the decrease of $D$, resulting in the highest friction occurring in Case $H^{c} D^{c}$, and the lowest friction taking place in Case $H^{a} D^{a}$. Correspondingly, $\bar{T}_{1}^{\max }$ has its maximum in Case $H^{c} D^{c}$ and its minimum in Case $H^{a} D^{a}$ - This observation applies for all the three rolling velocities covering the range $0.5 \leq u_{r} \leq 10 \mathrm{~m} / \mathrm{s}$. It is noted that although $\bar{\mu}$ increases as the rolling velocity decreases, $\bar{T}_{1}^{\max }$ decreases. This is because the frictional heat flux within the contact zone is reduced when the sliding velocity $u_{S}=u_{r} S R$ decreases with $u_{r}$ (The slide-to-roll ratio is fixed in this study.), despite the slight increase in the friction coefficient. The same can be concluded for the medium load $p_{h}=1.5 \mathrm{GPa}$ and the highest load $p_{h}=2.5 \mathrm{GPa}$ in Figs. 3.17 and 3.18 , respectively. 
(a)
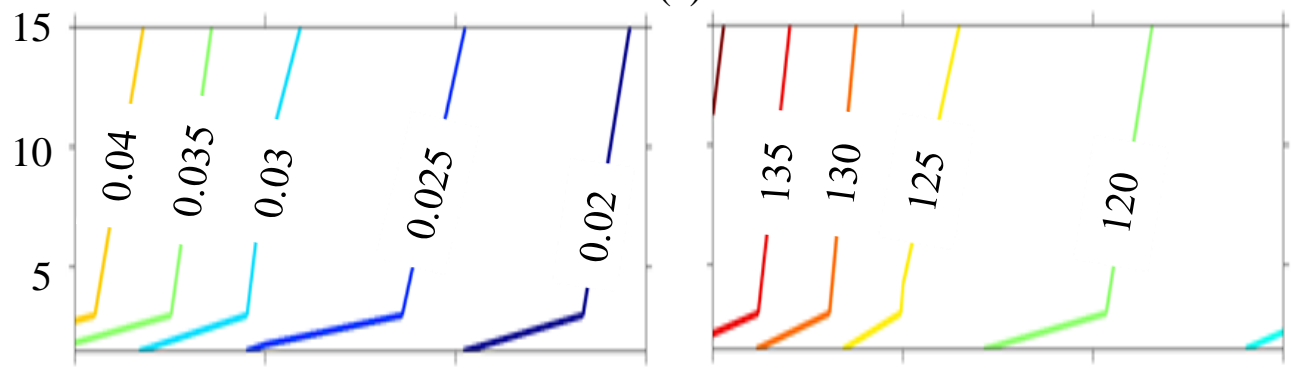

(b)
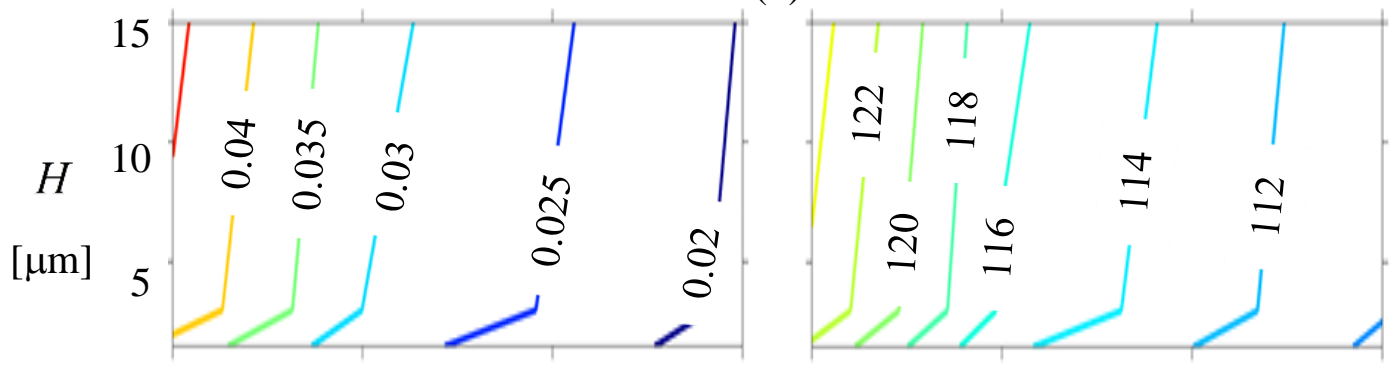

(c)

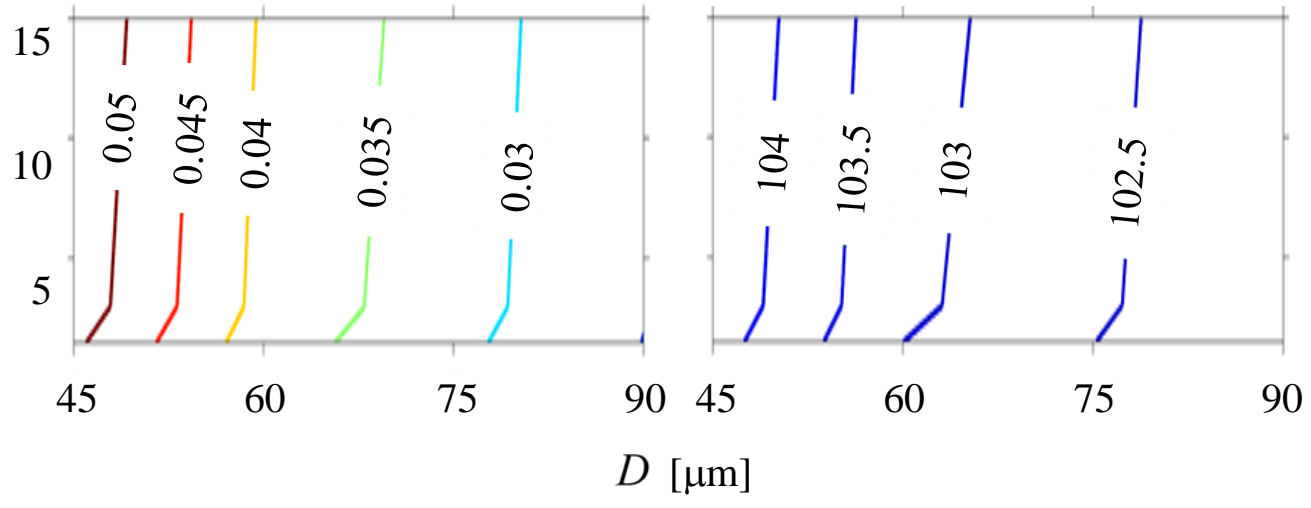

Figure 3-16 The variations of $\bar{\mu}$ (left column) and $\bar{T}_{1}^{\max }$ (right column) with the dimple center distance $D$ and the dimple depth $H$ at the rolling velocities (a) $u_{r}=10 \mathrm{~m} / \mathrm{s}$, (b) $u_{r}=5 \mathrm{~m} / \mathrm{s}$ and (c) $u_{r}=0.5$ $\mathrm{m} / \mathrm{s}$ and the lowest loading stage $p_{h}=0.5 \mathrm{GPa}$ for the type I surface texture combination (defined in Table 3.1). 
(a)
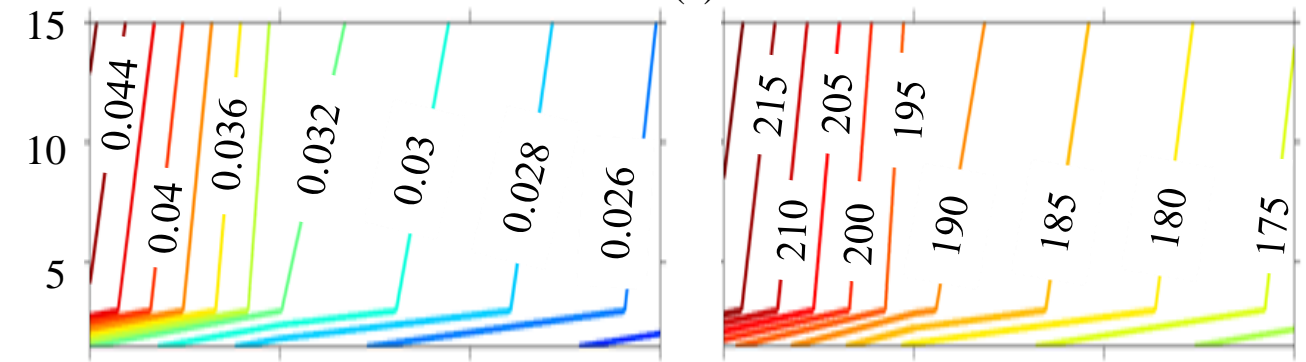

(b)

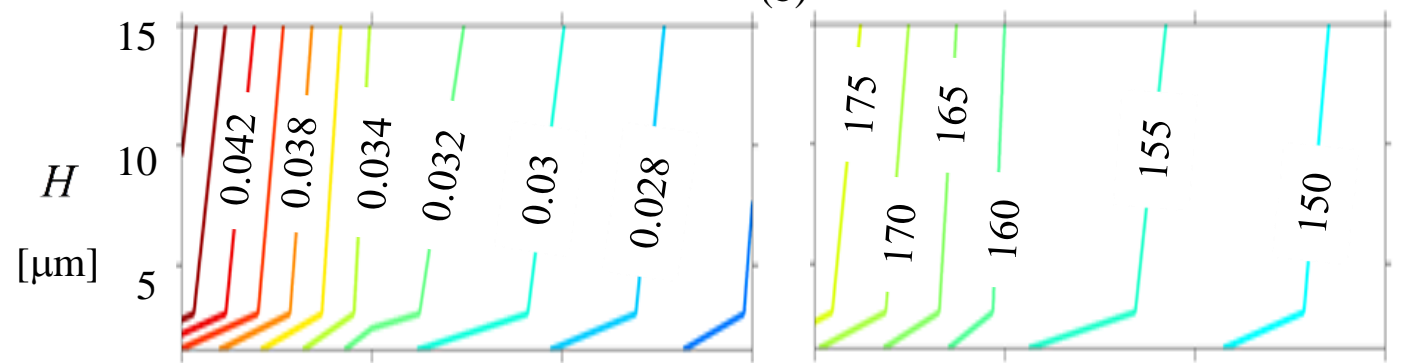

(c)

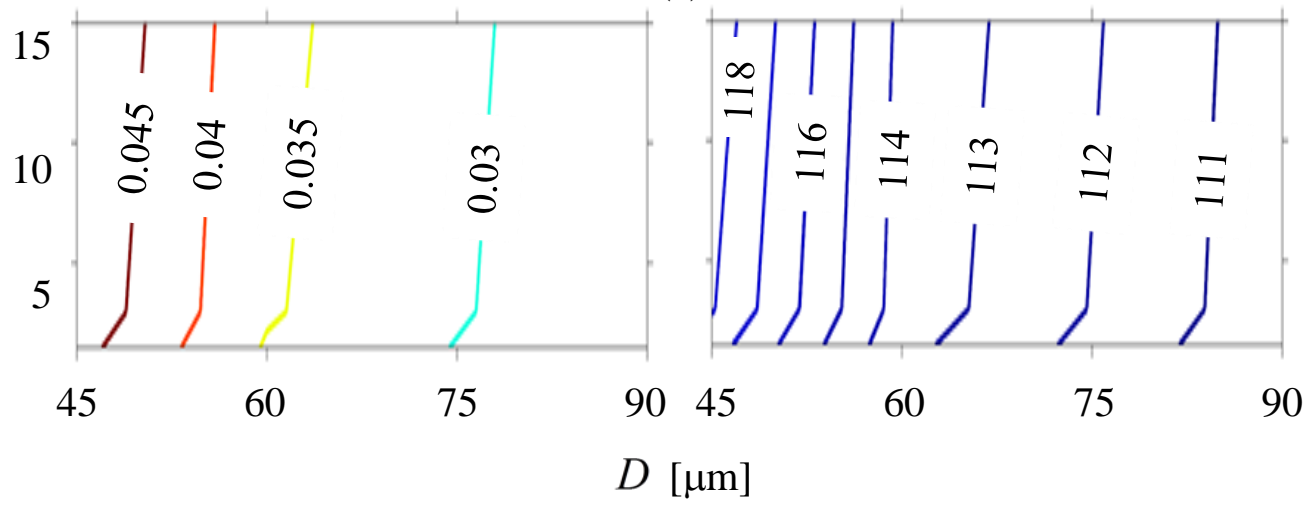

Figure 3-17 The variations of $\bar{\mu}$ (left column) and $\bar{T}_{1}^{\max }$ (right column) with the dimple center distance $D$ and the dimple depth $H$ at the rolling velocities (a) $u_{r}=10 \mathrm{~m} / \mathrm{s}$, (b) $u_{r}=5 \mathrm{~m} / \mathrm{s}$ and (c) $u_{r}=0.5$ $\mathrm{m} / \mathrm{s}$ and the median loading stage $p_{h}=1.5 \mathrm{GPa}$ for the type I surface texture combination (defined in Table 3.1). 
(a)
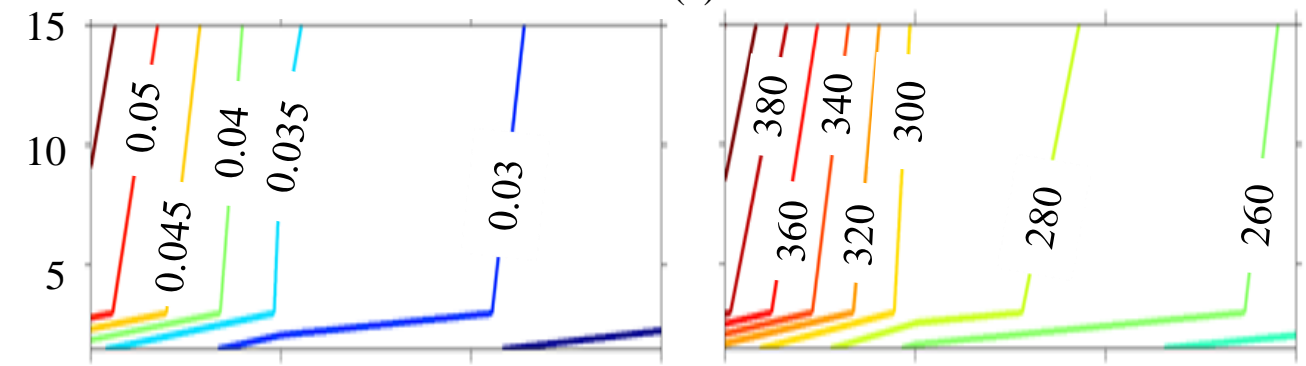

(b)
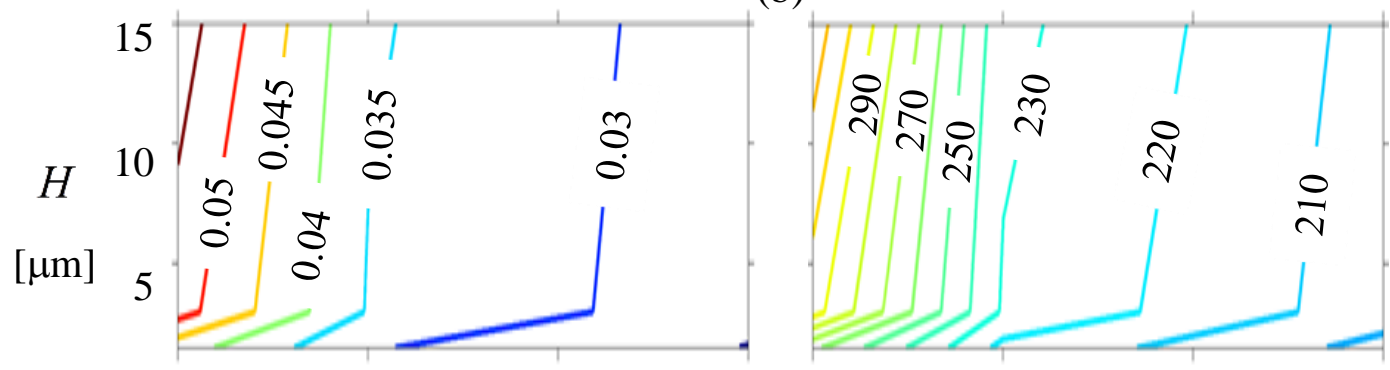

(c)

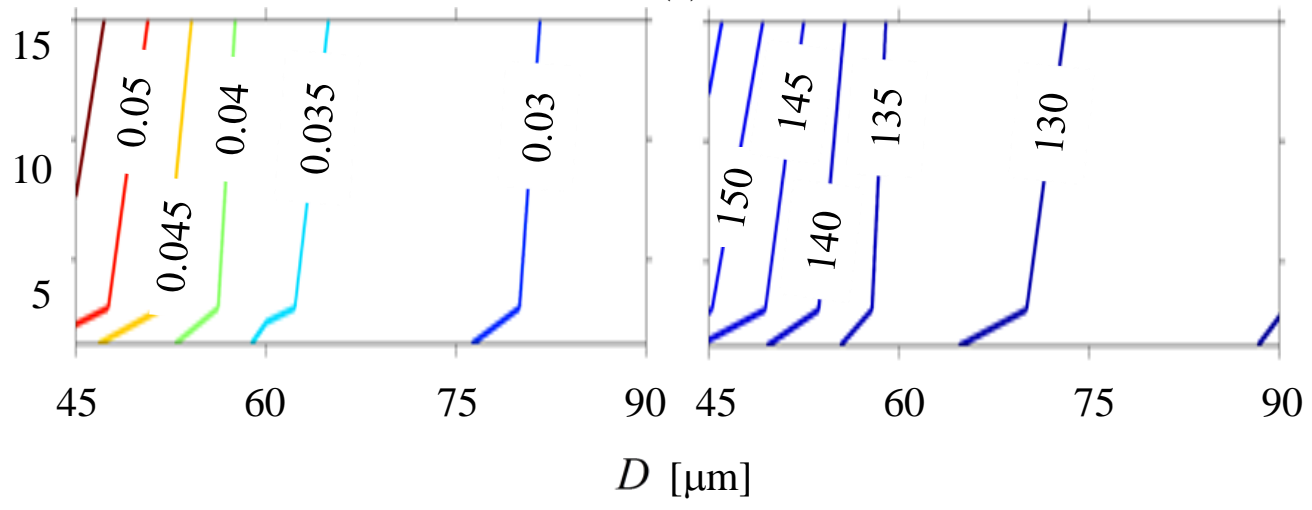

Figure 3-18 The variations of $\bar{\mu}$ (left column) and $\bar{T}_{1}^{\max }$ (right column) with the dimple center distance $D$ and the dimple depth $H$ at the rolling velocities (a) $u_{r}=10 \mathrm{~m} / \mathrm{s}$, (b) $u_{r}=5 \mathrm{~m} / \mathrm{s}$ and (c) $u_{r}=0.5$ $\mathrm{m} / \mathrm{s}$ and the highest loading stage $p_{h}=2.5 \mathrm{GPa}$ for the type I surface texture combination (defined in Table 3.1). 
In view of the above comparisons, the dimple array defined by Case $H^{a} D^{a}$ has the best performance in terms of the friction and the ball surface temperature. Using the type I surface texture combination with the $H^{a} D^{a}$ dimple array as the baseline, it is compared to the type II and type III surface texture combinations in Fig. 3.19 in terms of $\bar{\mu}$. Within the entire pressure range and the rolling velocity range, the ground surfaces of Type III combination are seen to lead to the highest friction owing to the significant surface roughness condition as shown in Fig. 3.3. The polished surfaces of Type II combination results in the lowest friction and the baseline offers the performance that is in between. Figure 3.20 shows the asperity contact activity and the contact pressure under these three surface texture conditions at the $10 \mathrm{~m} / \mathrm{s}$ rolling velocity and the $2.5 \mathrm{GPa}$ maximum Hertzian pressure. Comparing Fig. 20 (a) and (b), the addition of the dimples on the ball surface introduces more asperity contacts along the dimple circumferences and significant hydrodynamic pressure tails, therefore, resulting in the friction increase. Figure 3.20 (c) demonstrates the severe asperity contact activity for the ground surfaces, which leads to the large areas of the substantial asperity contact pressures and consequently the large friction. The same type of comparison as that in Fig. 3.19 is performed for $\bar{T}_{1}^{\max }$ in Fig. 3.21 Corresponding to the friction performance, the type III and type II surfaces, respectively, have the highest and lowest $\bar{T}_{1}^{\max }$ and the baseline is again in between. 


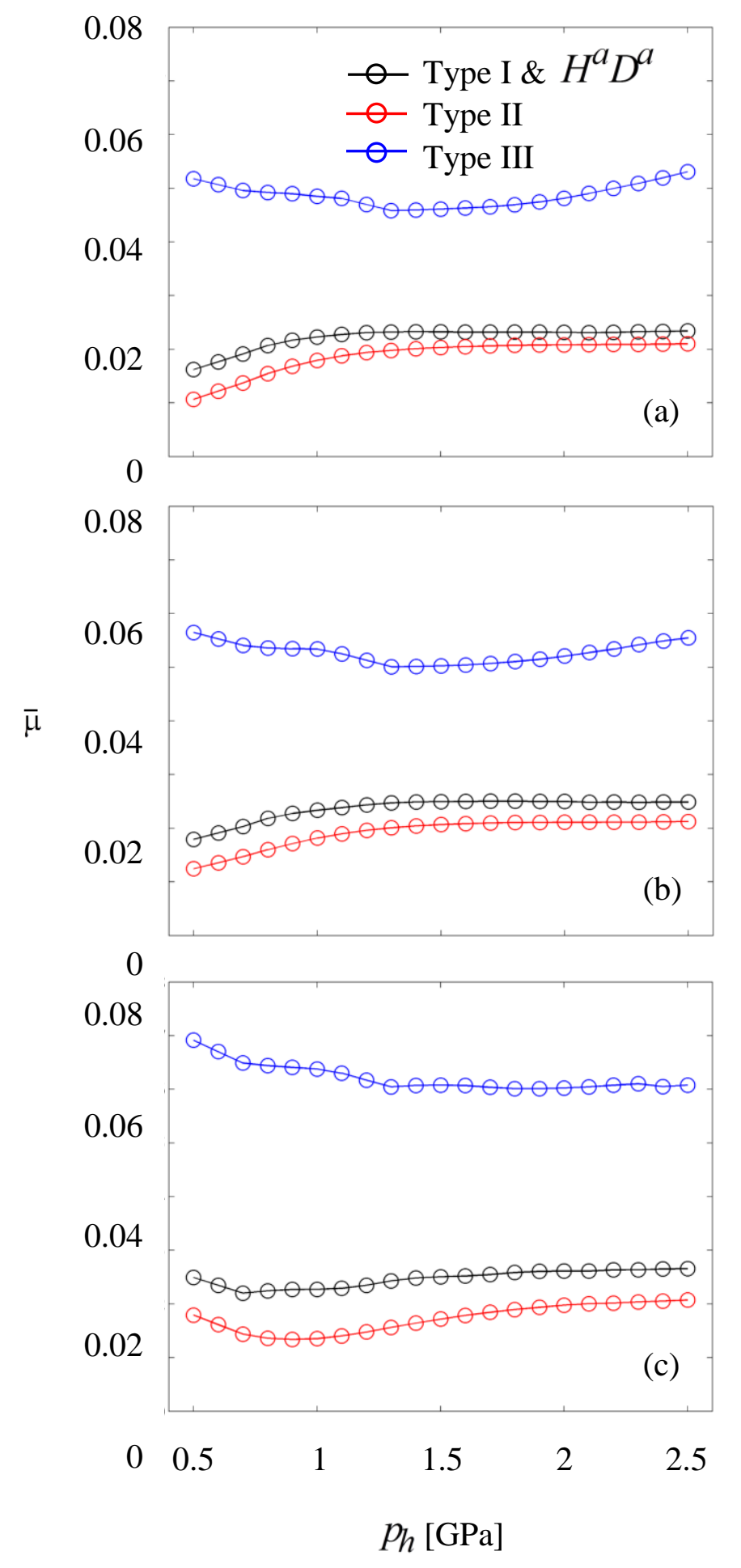

Figure 3-19 The comparisons of $\bar{\mu}$ between Type I (with $H^{a} D^{a}$ dimple array), II and III surface texture combinations under (a) $u_{r}=10 \mathrm{~m} / \mathrm{s}$, (b) $u_{r}=5 \mathrm{~m} / \mathrm{s}$ and (c) $u_{r}=0.5 \mathrm{~m} / \mathrm{s}$. 
(a)

[GPa]
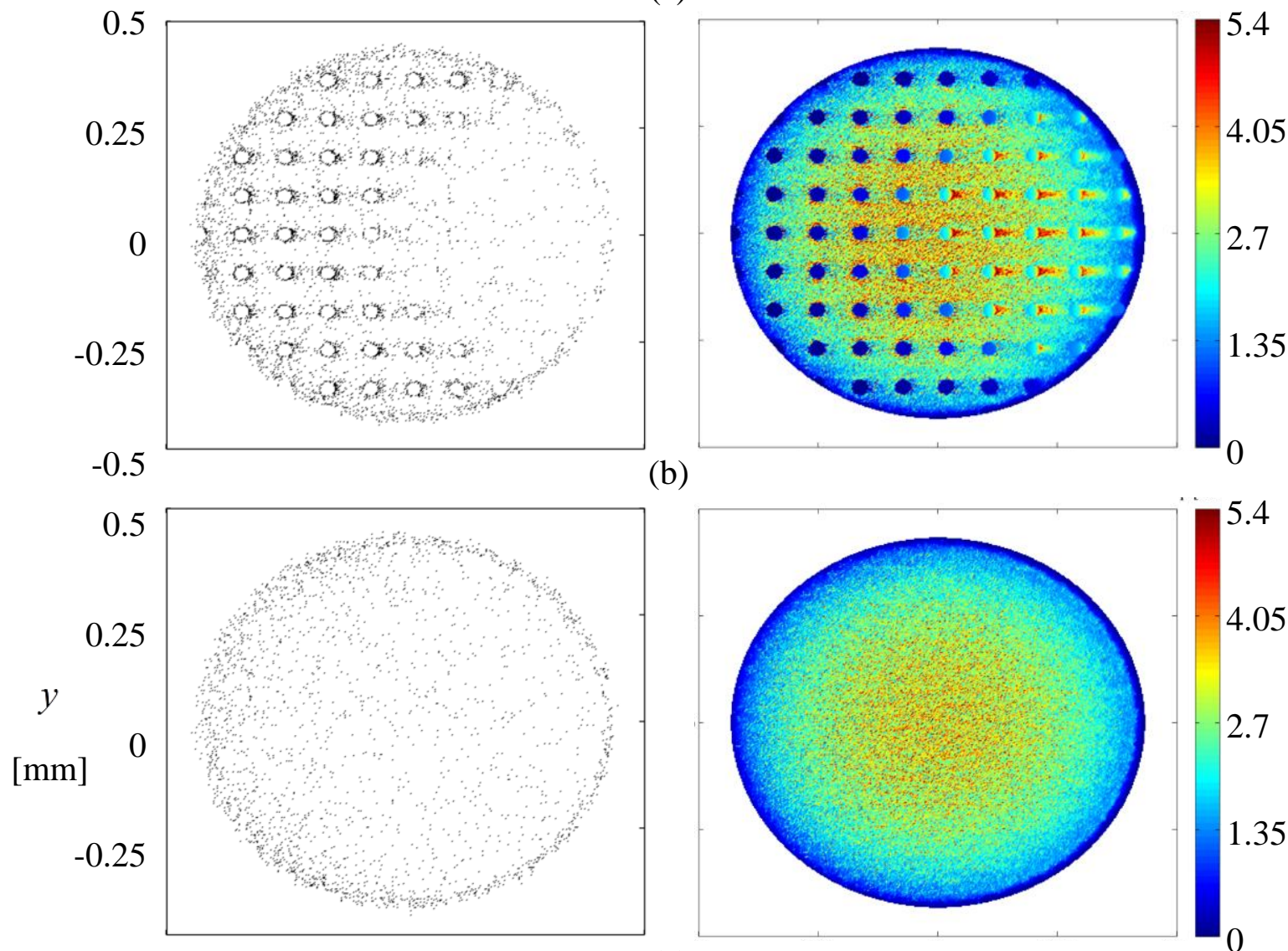

(b)
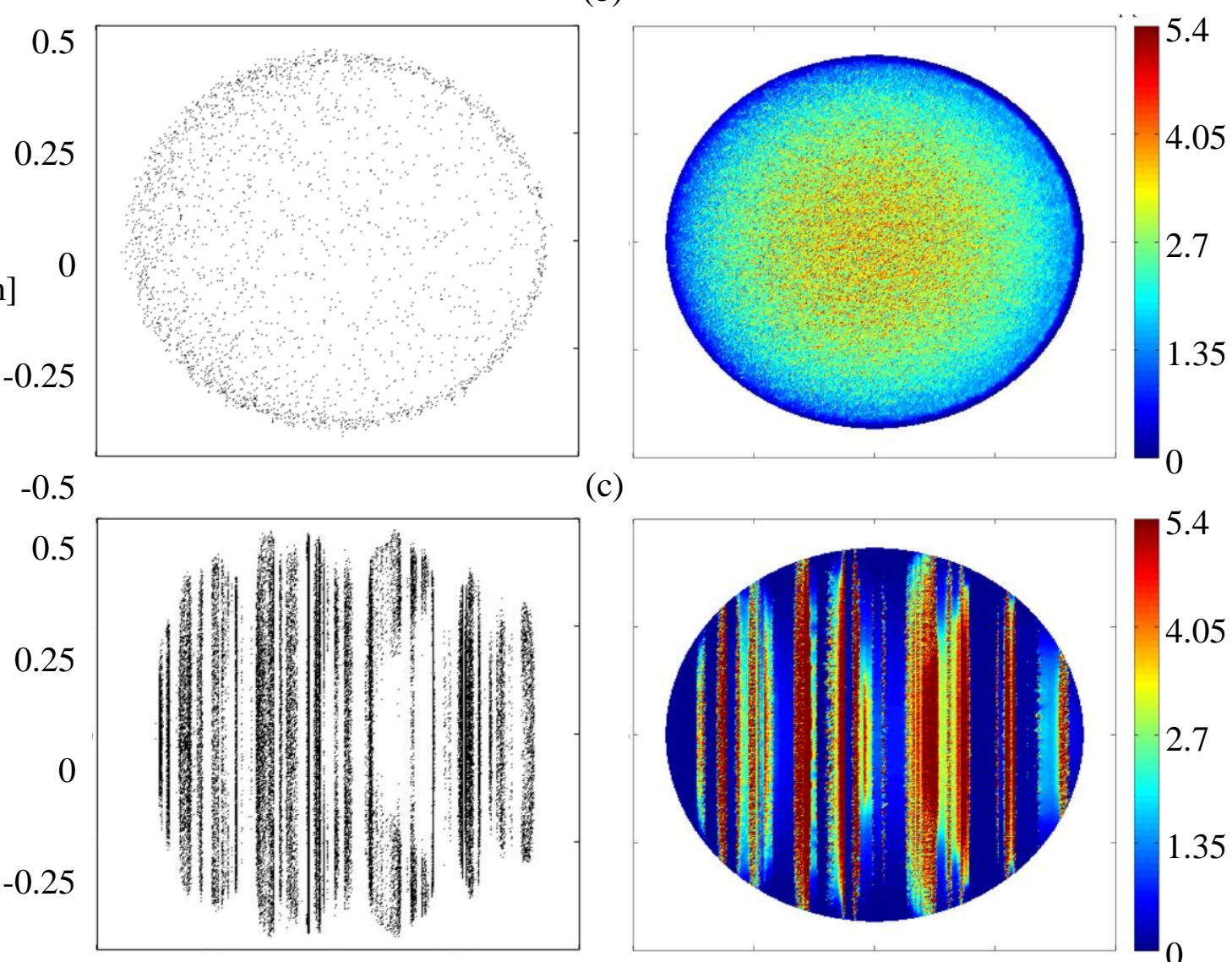

(c)

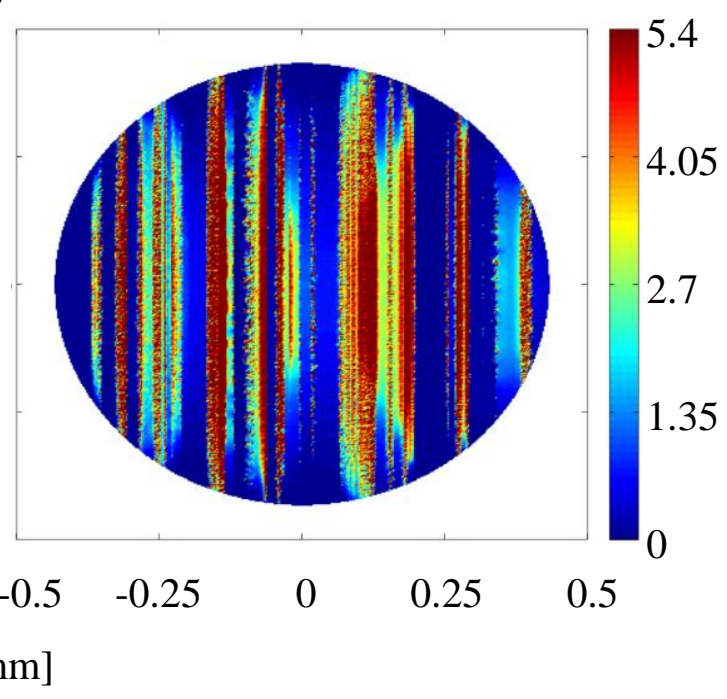

Figure 3-20 The comparisons of the asperity contact activity (left column) and the contact pressure (right column) between the surface texture combinations of (a) Type I with $H^{a} D^{a}$ dimple array, (b) Type II and (c) Type III within the Hertzian zone. $u_{r}=10 \mathrm{~m} / \mathrm{s}$, and $p_{h}=2.5 \mathrm{GPa}$. 


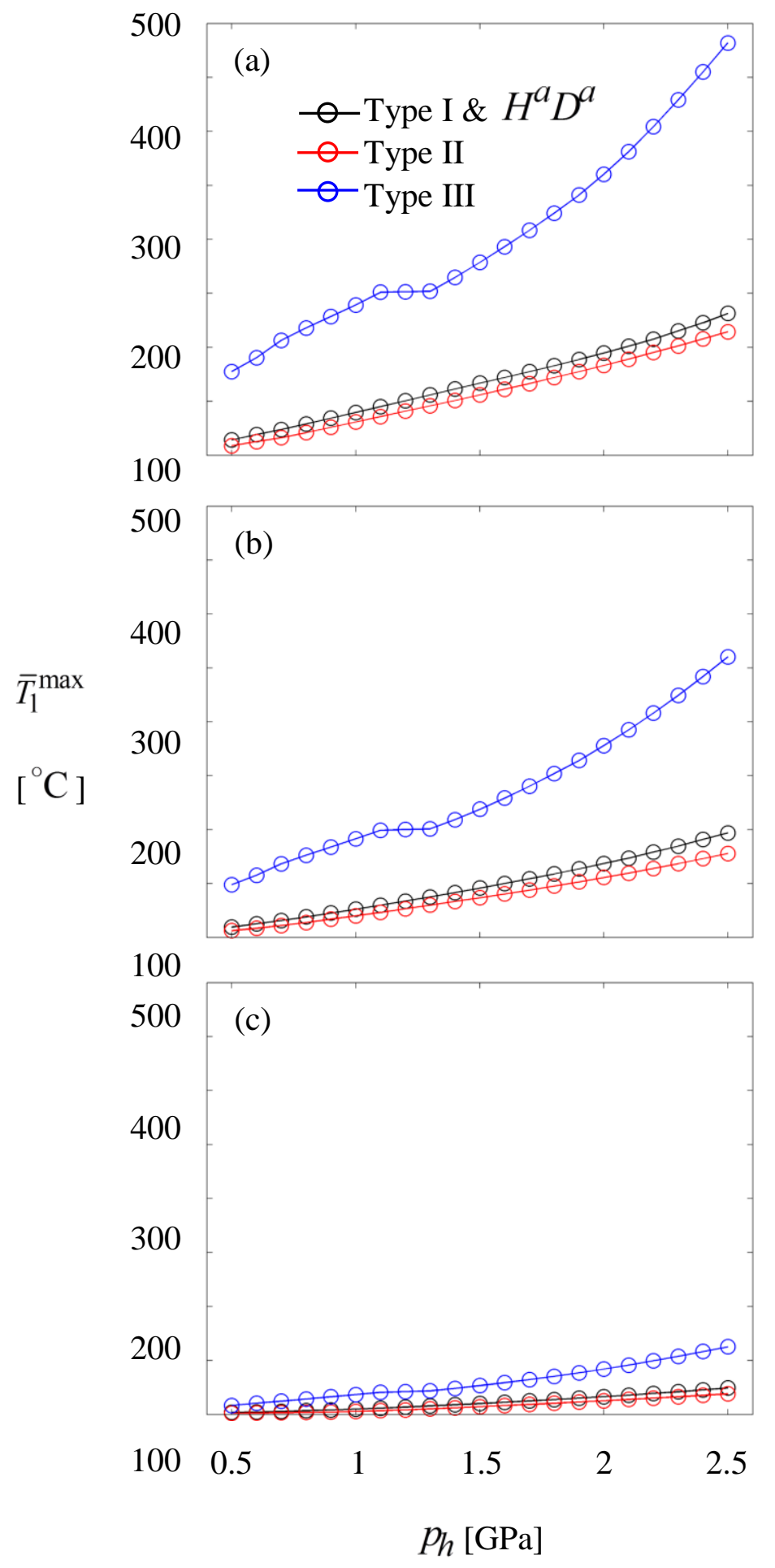

Figure 3-21 The comparisons of $\bar{T}_{1}^{\max }$ between Type I (with $H^{a} D^{a}$ dimple array), II and III surface texture combinations under (a) $u_{r}=10 \mathrm{~m} / \mathrm{s}$, (b) $u_{r}=5 \mathrm{~m} / \mathrm{s}$ and (c) $u_{r}=0.5 \mathrm{~m} / \mathrm{s}$. 


\section{CHAPTER 4}

\section{CONCLUSION}

\subsection{Conclusions}

Considering a ball-on-disk contact problem, this study investigated the influences of the micro-dimple texture on the friction and surface temperature performances of engineered rough surfaces, operating under wide speed and load ranges that cover typical gearing applications. Circular shaped micro-dimple arrays with different dimple center distances and dimple depths were implemented on the ball surface to quantify the impacts of these two parameters on the friction coefficient and the maximum ball surface temperature. It was shown both the friction and the surface temperature decrease with the increase of the dimple center distance and the decrease of the dimple depth within the entire speed and load ranges adopted. In addition, the contacts of three surface texture Combinations, namely micro-dimpled and polished ball surface versus polished disk surface, polished ball surface versus polished disk surface and ground ball surface versus ground disk surface, were compared to show detrimental impact of micro-dimples. 
By examining the deterministic tribological behavior within the contact, including the asperity contact activity and the contact pressure distribution, the underlying mechanisms are summarized as (i) the introduction of the micro-dimples increases the asperity contact activity along the dimple circumferences; (ii) the micro-dimples act as micro-bearings and results in significant hydrodynamic pressure tails starting from the right edges of the dimples. Both the high asperity contact pressures and the high micro-EHD hydrodynamic pressures contribute to the increase in the friction coefficient and consequently the surface temperature.

\subsection{Recommendation for Future Work}

Besides the dimple center distance and the dimple depth, the other influential parameters of a dimple array include the shape of the dimple (circular, rectangular, triangular, etc.) and the size of the dimple. Additionally a dimple array can consists of dimples with different shapes instead of one. All such parameters are not considered in this study. The comparison of the friction and temperature performances between surfaces with and without micro-dimples were only performed for polished surfaces. The operating speed range also only represents a medium to high gearing application range. Therefore, the following works are recommended for the future study:

- Examine the effects of the circular dimple radius;

- Investigate the effects of micro-dimples with other shapes;

- Construct hybrid dimple arrays with multiple dimple shapes coexisting, and compare with the conventional dimple arrays with a single dimple shape;

- Extend the speed parameter to a lower range, where heavy machinery operates; 
- Investigate the dimple effects on contact fatigue. 


\section{REFERENCES}

[1] Li, S., and Kahraman, A., 2010, "Prediction of spur gear mechanical power losses using a transient elastohydrodynamic lubrication model," Tribology Transaction, 53(4), pp. 554-563.

[2] Kolivand M., Li S., Kahraman A., 2010, "Prediction of mechanical gear mesh efficiency of hypoid gear pairs," Mechanisms and Machine Theory, 45(11), pp. 1555-1567. [3] Li S., 2015, "A thermal tribo-dynamic mechanical power loss model for spur gear contacts,” Tribology International, 88, pp. 170-178.

[4] Etsion, I., 2005, "State of the art in laser surface texturing," ASME Journal of Tribology, 127(1), pp. 248-253.

[5] Kovalchenko, A., Ajayi, O., Erdemir, A. and Fenske, G., 2011, "Friction and wear behavior of laser textured surface under lubricated initial point contact," Wear, 271, pp. $1719-1725$.

[6] Janakiraman V., Li S., Kahraman A., 2014, "An investigation of the impacts of contact parameters on wear coefficient," ASME Journal of Tribology, 136, 031602 (7 pages).

[7] Akamatsu, Y., Tsushima, N., Goto, T. and Hibi, K., 1992, "Influence of surface roughness skewness on rolling contact fatigue life," Tribology Transactions, 35(4), pp. $745-750$. 
[8] Zhai, X., Chang, L., Hoeprich, M.R. and Nixon, H.P., 1997, "On mechanisms of fatigue life enhancement by surface dents in heavily loaded rolling line contacts," Tribology Transactions, 40(4), pp. 708-714.

[9] Krupka, I., Vrbka, M. and Hartl, M., 2008, "Effect of surface texturing on mixed lubricated non-conformal contacts,” Tribology International, 41, pp. 1063-1073.

[10] Vrbka, M., Samanek, O., Sperka, P., Navrat, T., Krupka, I. and Hartl, M., 2010, "Effect of surface texturing on rolling contact fatigue within mixed lubricated nonconformal rolling/sliding contacts,” Tribology International, 43, pp. 1457-1465.

[11] Li S., and Kahraman A., 2011, "A fatigue model for contacts under mixed elastohydrodynamic lubrication condition," International Journal of Fatigue, 33(3), pp. $427-436$.

[12] Li S., 2015, "A computational study on the influence of surface roughness lay directionality on micropitting of lubricated point contacts," ASME Journal of Tribology, 137(2), 021401 (10 pages).

[13] Nakatsuji, T. and Mori, A., 2001, "The tribological effect of mechanically produced micro-dents by a micro diamond pyramid on medium carbon steel surfaces in rollingsliding contact,” Meccanica, 36, pp. 663-674.

[14] Li, S., 2013, "Influence of surface roughness lay directionality on scuffing failure of lubricated point contacts," ASME Journal of Tribology, 135(4), 041502 (10 pages).

[15] Li, S., Kahraman, A., Anderson N. E., and Wedeven, L. D., 2013, “A model to predict scuffing failures of a ball-on-disk contact,” Tribology International, 60, pp. 233-245.

[16] Li S., and Kahraman A., 2009, "A mixed EHL model with asymmetric integrated control volume discretization,” Tribology International, 42(8), pp. 1163-1172. 
[17] Petry-Johnson, T., Kahraman, A., Anderson, N.E. and Chase, D., 2008, “An experimental investigation of spur gear efficiency," ASME Journal of Mechanical Design, 130(6), 062601 (10 pages).

[18] Li, S., Kahraman, A., and Klein, M., 2012, "A fatigue model for spur gear contacts operating under mixed elastohydrodynamic lubrication conditions," ASME Journal of Mechanical Design, 134(4), 041007 (11 pages).

[19] Li S., and Kahraman A., 2013, "Micro-pitting fatigue lives of lubricated point contacts: Experiments and model validation," International Journal of Fatigue, 48, pp. 9518.

[20] Patching, M. J., Kweh, C. C., Evans, H. P. and Snidle,R. W., 1995, "Conditions for scuffing failure of ground and superfinished steel disks at high sliding speeds using a gas turbine engine oil," Journal of Tribology, 117, pp. 482-489.

[21] Nakatsuji, T. and Mori, A., 1998, "Tribological properties of electrolytically polished surfaces of carbon steel,” Tribology Transactions, 41(2), pp. 179-188.

[22] Etsion, I. and Sher, E., 2009, "Improving fuel efficiency with laser surface textured piston rings," Tribology International, 42, pp. 542-547.

[23] Kovalchenko, A., Ajayi, O., Erdemir, A., Fenske, G. and Etsion, I., 2005, “The effect of laser surface texturing on transitions in lubrication regimes during unidirectional sliding contact," Tribology International, 38, pp. 219-225.

[24] Andersson, P., Koskinen, J., Varjus, S., Gerbig, Y., Haefke, H., Georgiou, S., Zhmud, B. and Buss, W., 2007, "Microlubrication effect by laser-textured steel surfaces," Wear, 262, pp. 369-379. 
[25] Galda, L., Pawlus, P. and Sep, J., 2009, "Dimples shape and distribution effect on characteristics of Stribeck curve,” Tribology International, 42, pp. 1505-1512.

[26] Qiu, Y. and Khonsari, M.M., 2011, "Experimental investigation of tribological performance of laser textured stainless steel rings," Tribology International, 44, pp. 635644.

[27] Segu, D.Z., Choi, S.G., Choi, J.H. and Kim, S.S., 2013, "The effect of multi-scale laser textured surface on lubrication regime," Applied Surface Science, 270, pp. 58-63.

[28] Wang, X., Liu, W., Zhou, F. and Zhu, D., 2009, "Preliminary investigation of the effect of dimple size on friction in line contacts," Tribology International, 42, pp. 11181123.

[29] Tang, W., Zhou, Y., Zhu, H. and Yang, H., 2013, "The effect of surface texturing on reducing the friction and wear of steel under lubricated sliding contact," Applied Surface Science, 273, pp. 199-204.

[30] Yu, H., Wang, X. and Zhou, F., 2010, "Geometric shape effects of surface texture on the generation of hydrodynamic pressure between conformal contacting surfaces," Tribology Letters, 37, pp. 123-130.

[31] Brunetiere, N. and Tournerie, B., 2012, "Numerical analysis of a surface-textured mechanical seal operating in mixed lubrication regime," Tribology International, 49, pp. $80-89$.

[32] Segu, D.Z. and Kim, S.S., 2014, "Influence on friction behavior of micro-texturing under lubricated non-conformal contact," Meccanica, 49, pp. 483-492. 
[33] Wakuda, M., Yamauchi, Y., Kanzaki, S. and Yasuda, Y., 2003, "Effect of surface texturing on friction reduction between ceramic and steel materials under lubricated sliding contact," Wear, 254, pp. 356-363.

[34] Meng, F., Zhou, R., Davis, T., Cao, J., Wang, Q.J., Hua, D. and Liu, J., 2010, “Study on effect of dimples on friction of parallel surfaces under different sliding conditions," Applied Surface Science, 256, pp. 2863-2875.

[35] Johnson K. L., Contact Mechanics, Cambridge University Press, Cambridge, 1985.

[36] Kim, K. H. and Sadeghi, F., 1992, "Three-dimensional temperature distribution in EHD lubrication. Part I: circular contact,” ASME Journal of Tribology, 114(1), pp. 32-41. [37] Carslaw, H. S. and Jaeger, J. C., Conduction of Heat in Solids, Oxford Press, 1959.

[38] Li, S. and Anisetti, A., 2016, "On the flash temperature of gear contact under the tribo-dynamic condition,” Tribology International, 97, pp. 6-13.

[39] Li, S. and Kahraman, A., 2011, "A method to derive friction and rolling power loss formulae for mixed EHL contacts," Journal of Advanced Mechanical Design, Systems, and Manufacturing, 5(4), pp. 252-263.

[40] Wedeven, L.D. and Cusano, C., 1979, "Elastohydrodynamic film thickness measurements of artificially produced surface dents and grooves," ASLE Transactions, 22(4), pp. 369-381.

[41] Cusano, C. and Wedeven, L.D., 1982, "The effects of artificially-produced defects on the film thickness distribution in sliding EHD point contacts," Journal of Lubrication Technology, 104, pp. 365-375.

[42] Liou, J.J., A theoretical and experimental investigation of roller and gear scuffing, PhD Dissertation, The Ohio State University, 2010. 